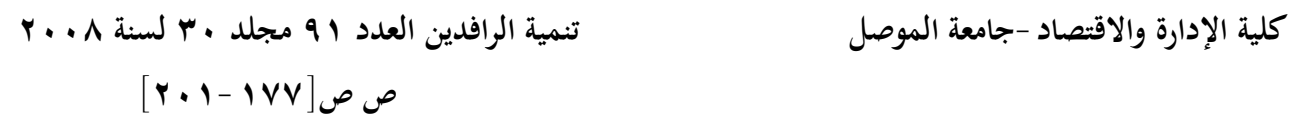

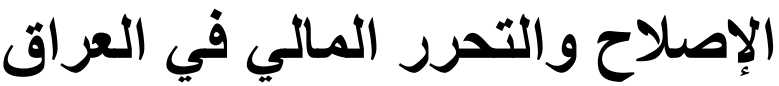 مع الإشارة للتجربة المصرية المصية
}

$$
\text { مدرس مساعد -قسم العلوم المالية والمصرفية الإدارة والاقتصاد - جمامعة الموصل }
$$

Zahraa.ahmed@ymail.com

$$
\begin{aligned}
& \text { عدي سالم علي الطائي } \\
& \text { مدرس مساعد -قسم العلوم المالية والمصرفية } \\
& \text { كلية الإدارة والاقتصاد -جامعة الموصل }
\end{aligned}
$$

Odaysalim20042005@yahoo.com

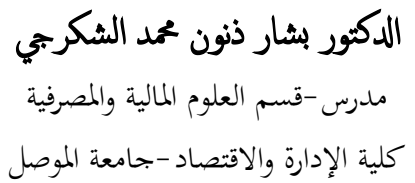

Bashar_thanoon@yahoo.com

\begin{abstract}
المستخلص

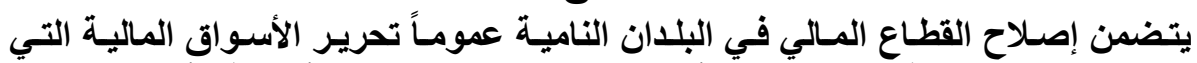

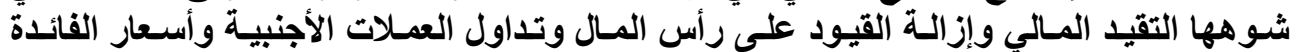

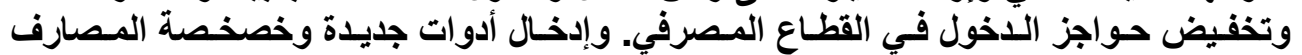

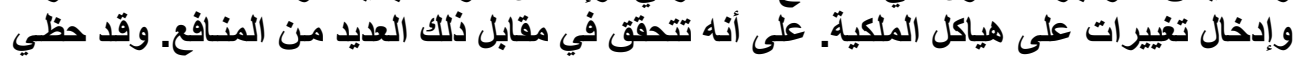

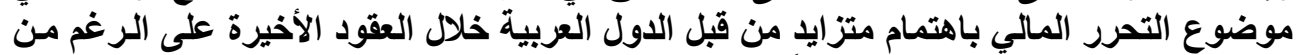

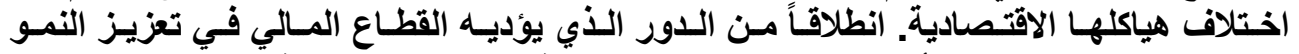

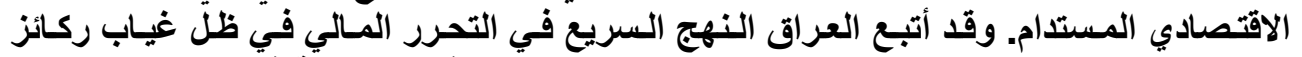

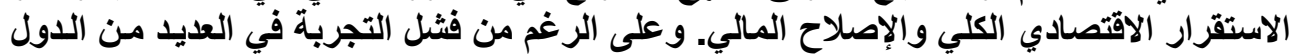

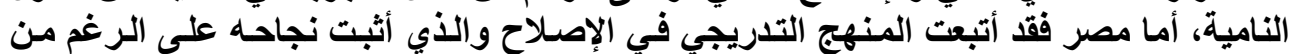

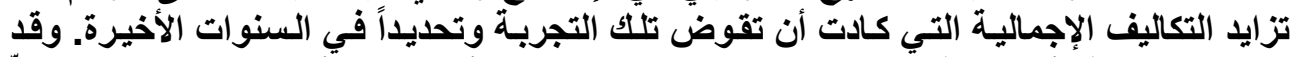

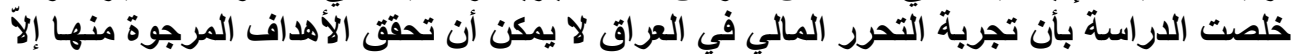

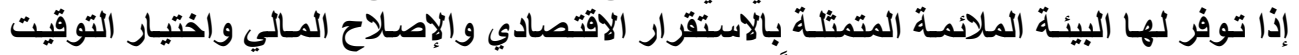

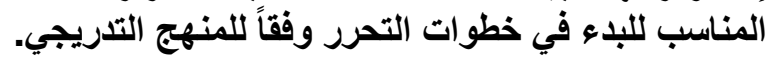

\section{The Financial Liberation and Reformation in I raq with Reference to Egyptian Experiment}

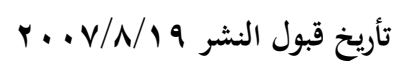

$$
\text { تاريخ استلام البحث r. v/V/T }
$$




\author{
Bashar Th. Al-Shakarji (PhD) \\ Lecturer \\ Department of Financial and \\ Banking Sciences \\ University of Mosul
}

\author{
Oday Salim Ali \\ Assist. Lecturer \\ Department of Financial \\ and Banking Sciences \\ University of Mosul
}

\author{
Zahraa' A. M. Al-Noa'imee \\ Assist. Lecturer \\ Department of Financial and Banking \\ Sciences \\ University of Mosul
}

\begin{abstract}
The financial sector in the growing countries generally includes the financial market liberation which is distorted by the financial restriction, the removal of the restraints on the capital, the circulation of foreign currency and interest rates, the decrease of joining barriers in the banking sector, the use of new means and privatization of banks and the introduction of changes on the ownership frameworks. All these are done in return for achieving several benefits. The subject of financial liberation has been of interest by the Arab countries during the last decades, in spite of the difference of their economical frameworks, because of the important role of financial sector in the reinforcing the economical increase. Iraq has followed the rapid method in the financial liberation in the absence of its support, which is represented by the economical stability and the financial reformation. However, Egypt has followed the gradual method in the reformation. The success of latter method is approved in spite of the increase of social cost which was about the collapse, defiantly in the last years. The study concluded that the financial liberation experiment is not able to achieve its looking for aims in Iraq only if the fitting environment which is manifested by this economic stability and the financial reformation exist and suitable timing to begin with the liberation steps according to the gradual method is chosen.
\end{abstract}

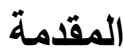

يقصد بالتحرر المالي فتح الأسواق المالية والر أسمالية أمسام الشركات الأجنبية

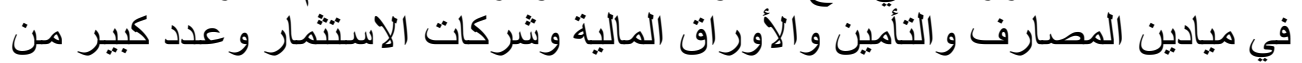

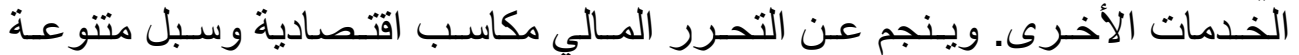

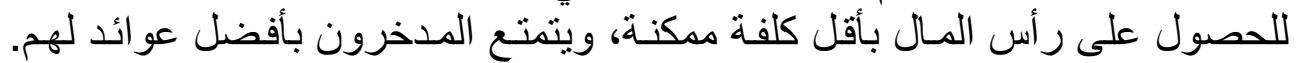

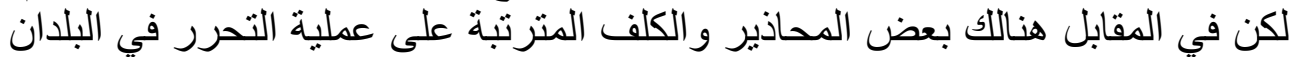

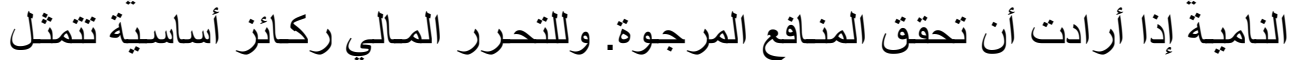

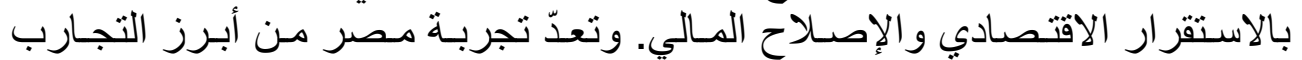

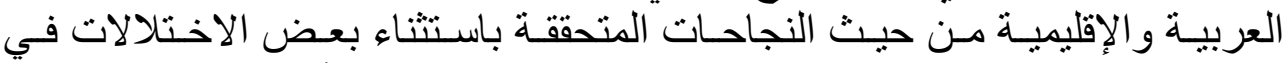

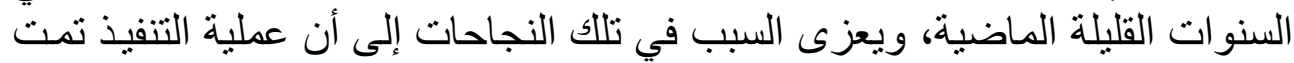

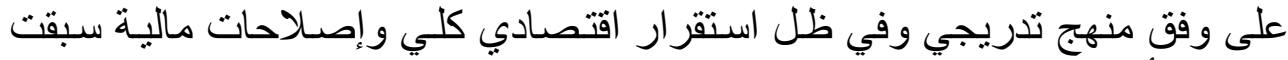

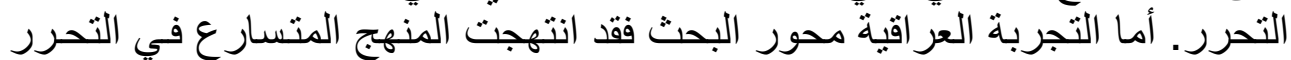

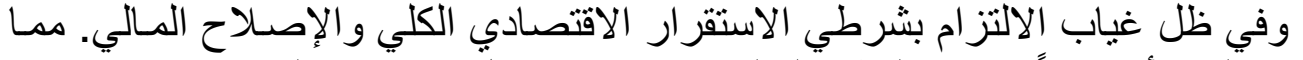

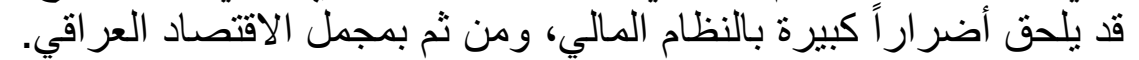

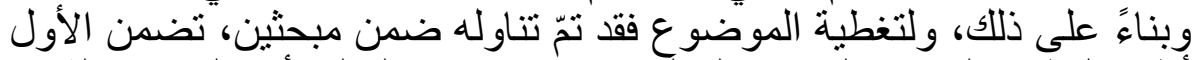

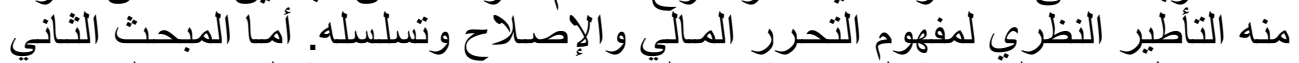

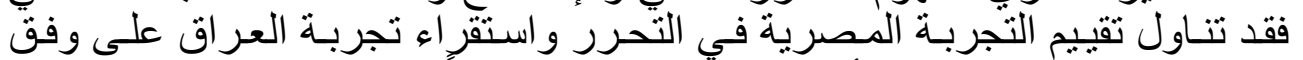

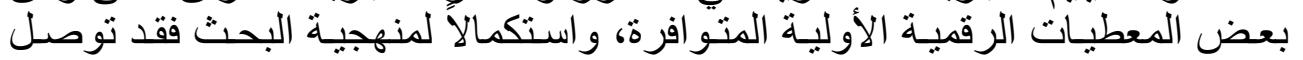

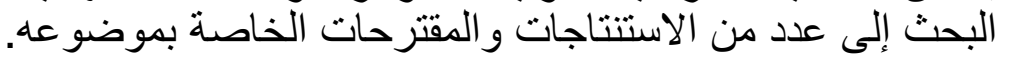




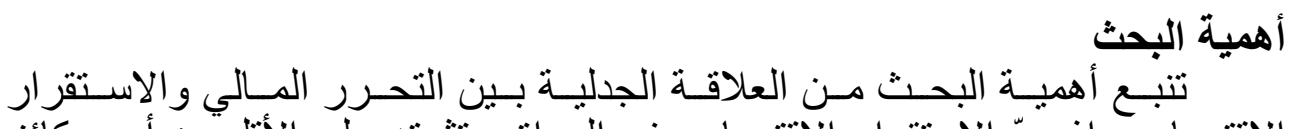

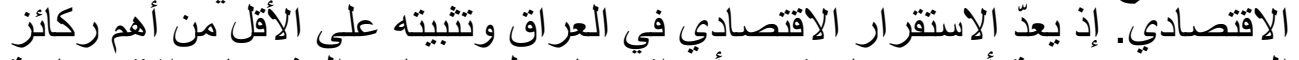

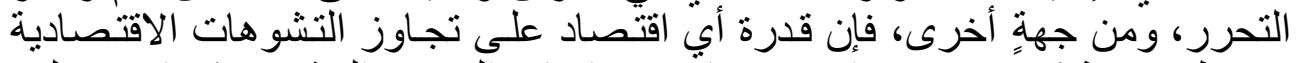

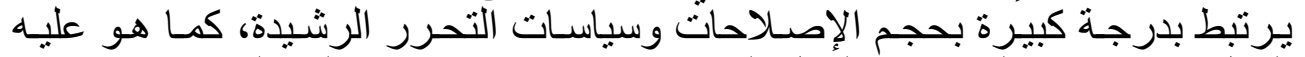

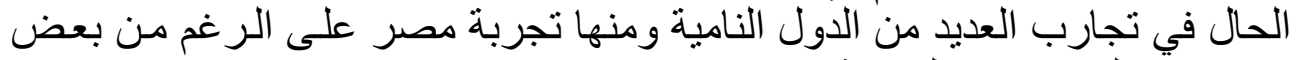

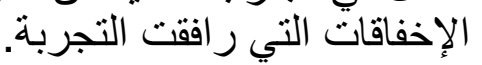

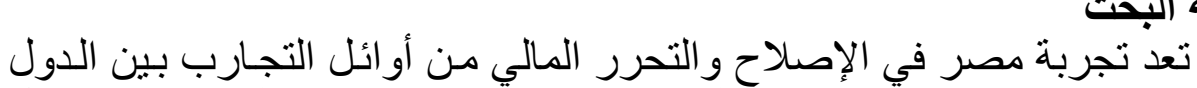

\section{مشكلة البحث}

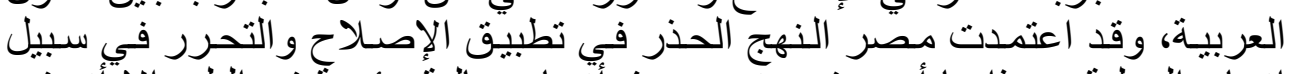

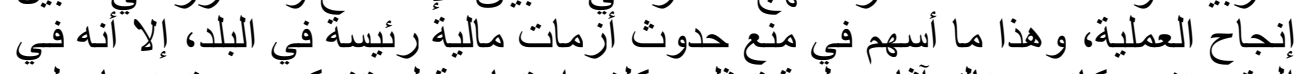

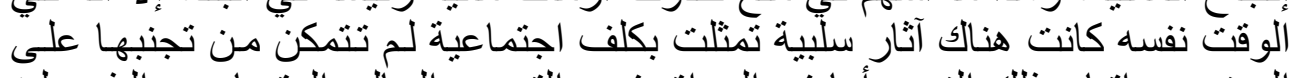

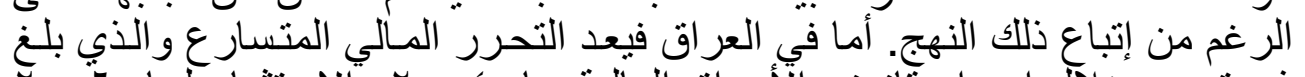

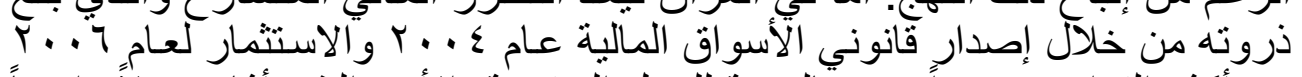

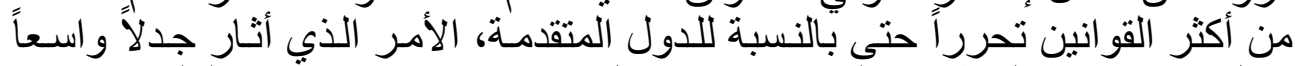

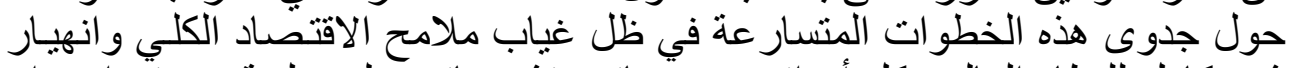

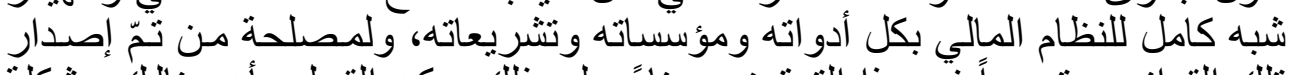

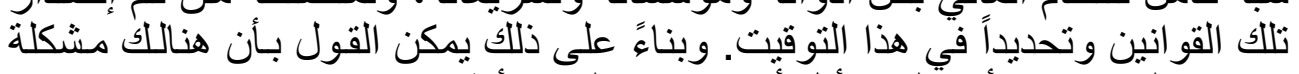

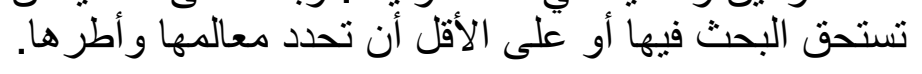

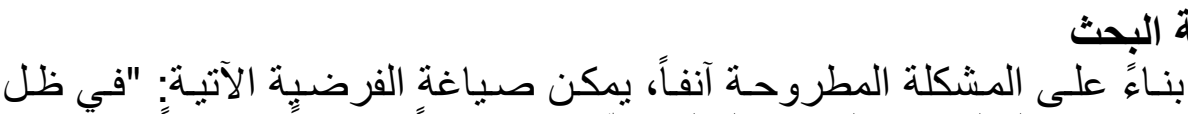

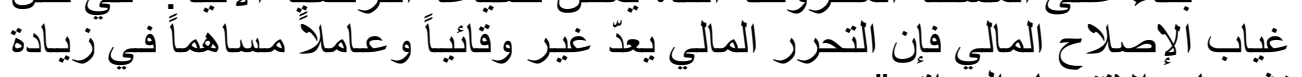
تشوهات الإقتصاد العز اقي".

يُّذف البحث إلى تحقيق ما يأتي:

\section{هدف البحث}

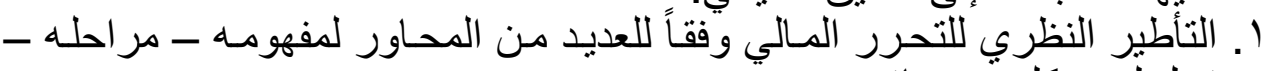

تسلسله - كلفه - منافعه.

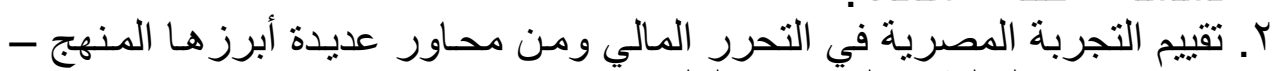

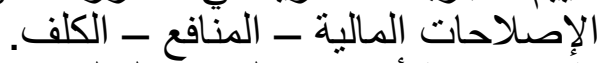

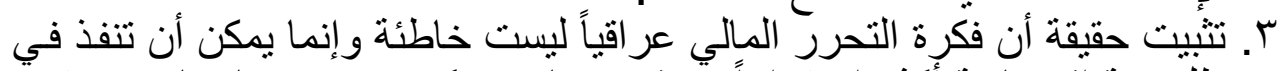

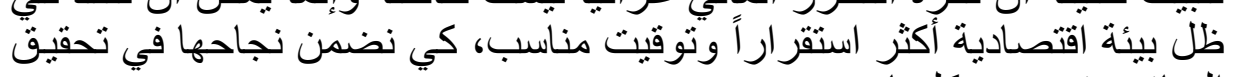

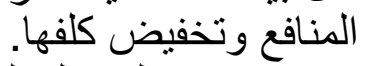

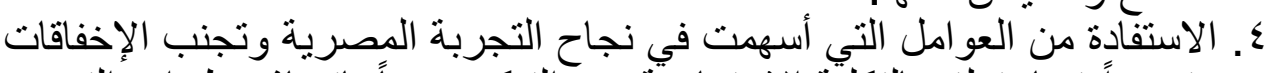

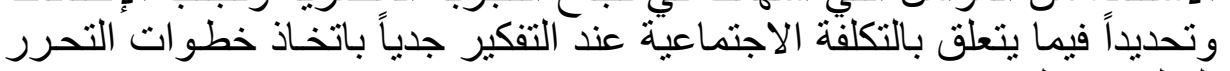

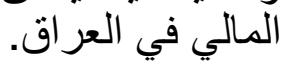


اعتمد البحث على المنهج الوصفي، إذ تمت الاستعانة بالبحوث و والدر اسـات

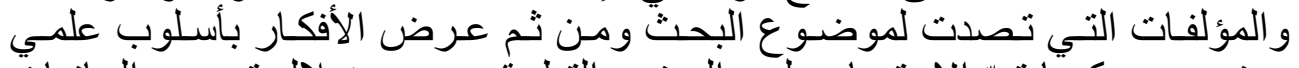

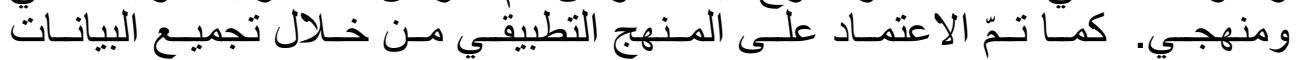

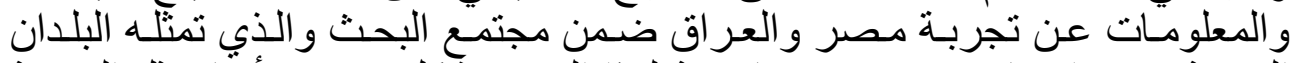

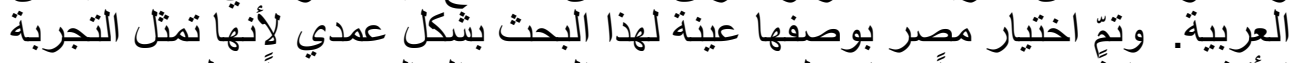

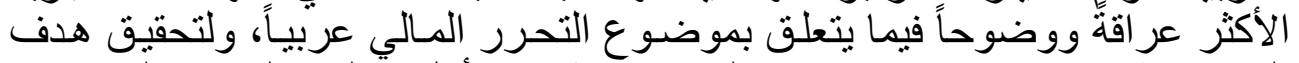

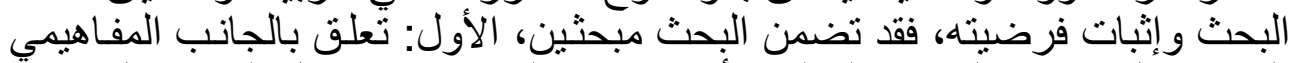

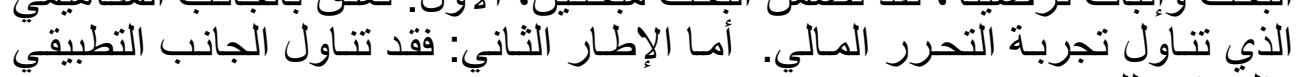
و المئيداني للبحث.

\section{ألإصِلاح والتحرر المالي: تأطير مفاهيمي

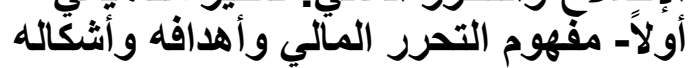

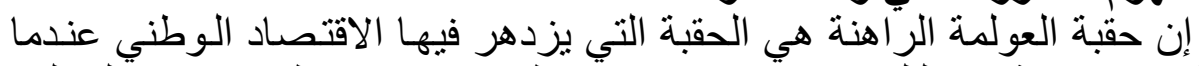

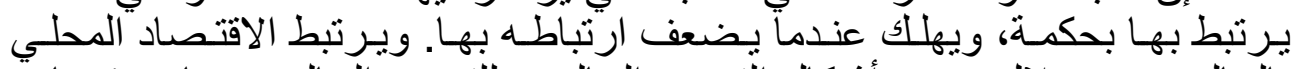

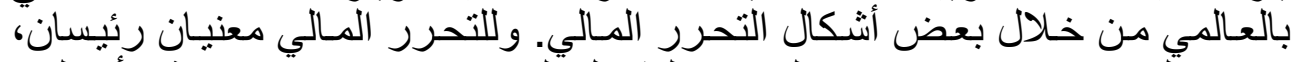

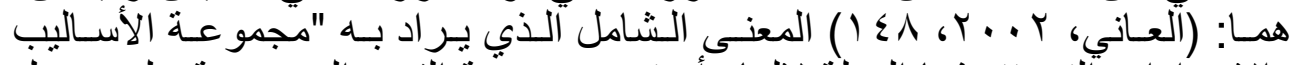

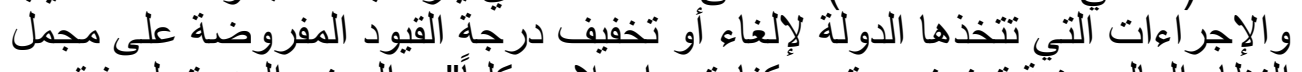

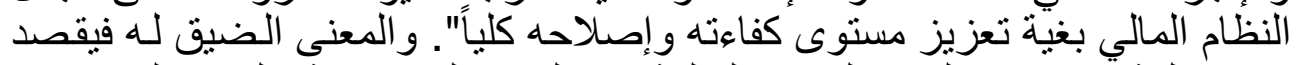

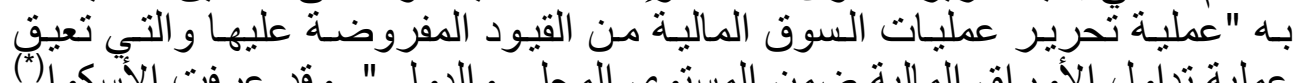

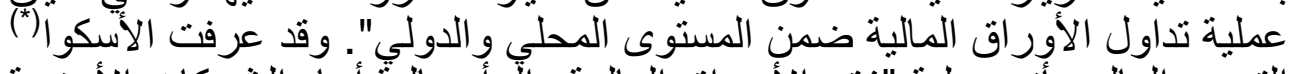

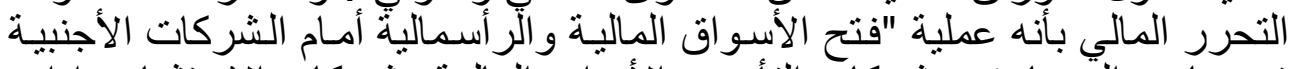

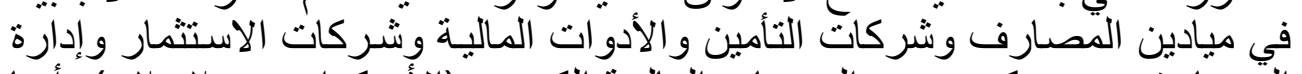

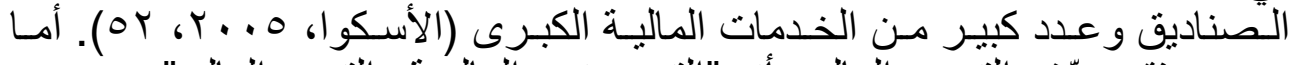

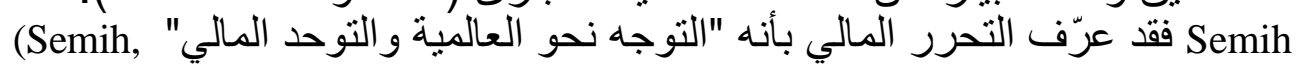
وتسعى الدول التي تتبنى سياسة التحرر المالي إلى تحقيق العديد من الأهداف .2003, 21)

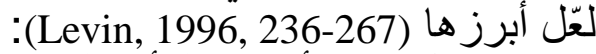
ا ـ الوصول إلى الأسواق الر أسمالية الدولية.

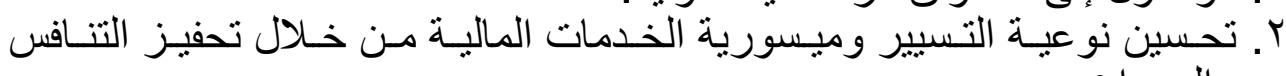

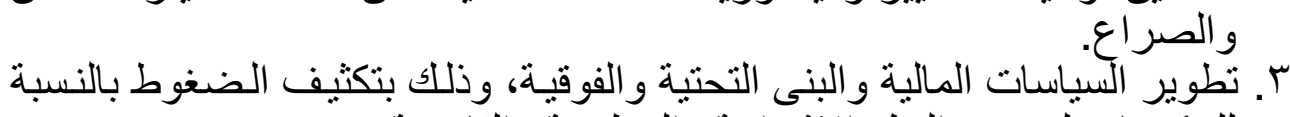

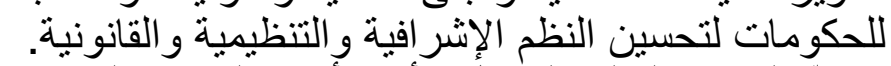
ويعدّ التحرر المالي المدخل الأكثر أهمية لتعزيز التنافسية، ويمكن تحقيقه بثلاثنة

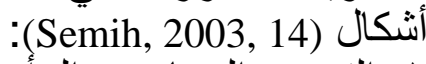

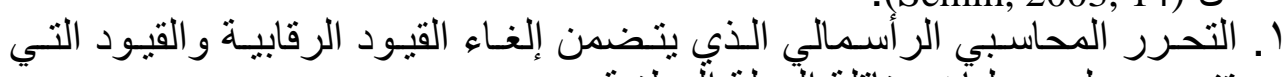
تفرض على عمليات مناقلة التعلة ألوطنية. 


\section{دكتور الشكرجي والطائي والنعيمي [111]}

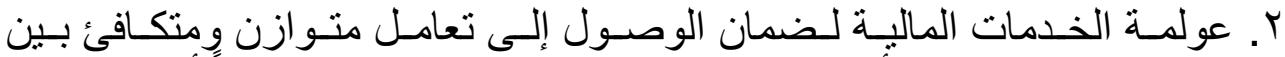

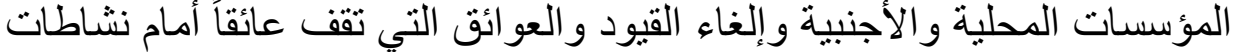

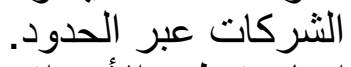

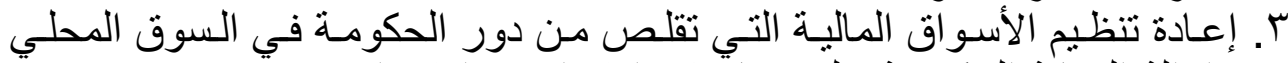

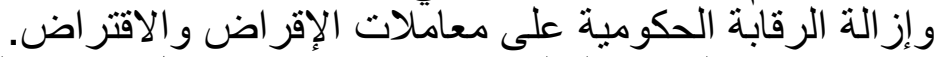

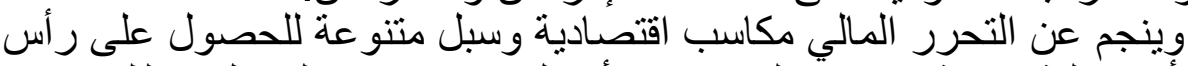

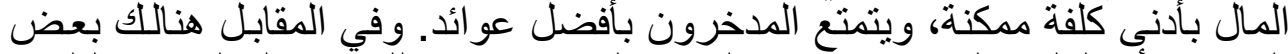

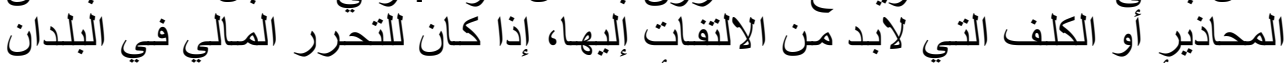

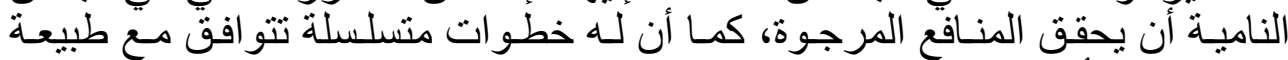

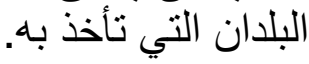

\section{ثانياً. تسلسل التحرر المالي ومستوياته}

توجد العديد من الدرأسات التطبيقية والنظرية التي تركز على تسلسل النسل التحرر

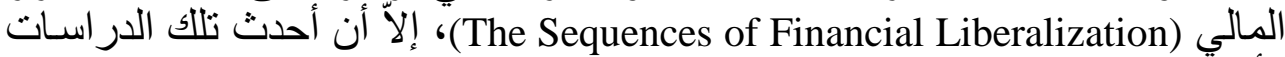

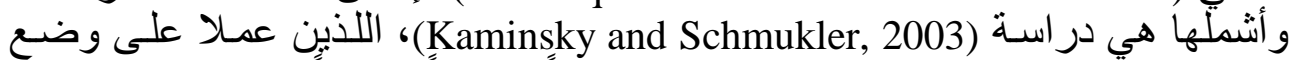

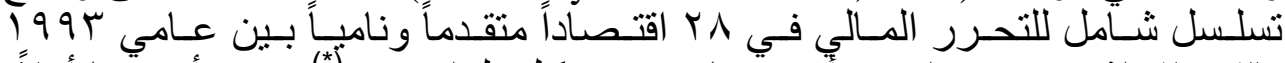

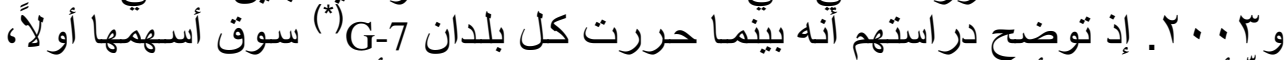
إلاّ أن البلدان الأوربية اتبعت إستراتيجية مزيجة، فربما قد أز ال التنظيم في قطاعها

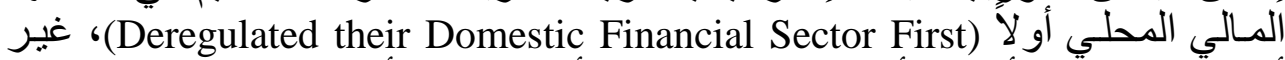
أن معظمها حرر أسواق أسهمه، و النتيجة هي أن تحرير الأسواق المالية المحلية كان

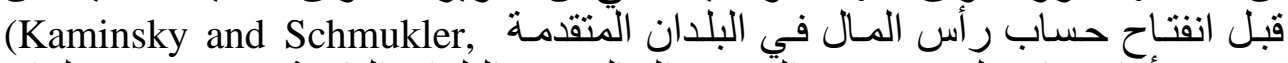

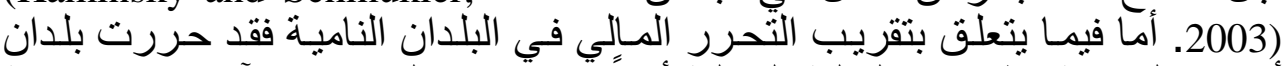

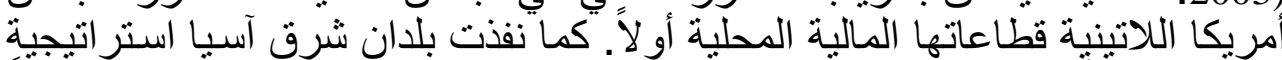

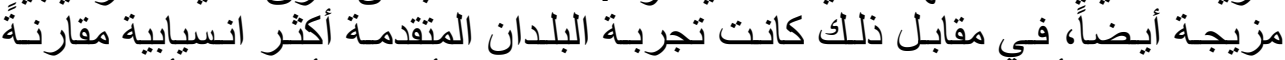

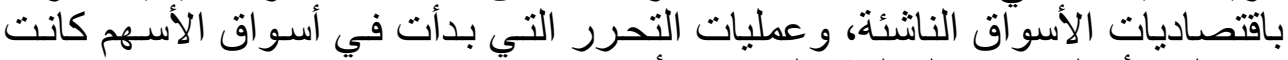

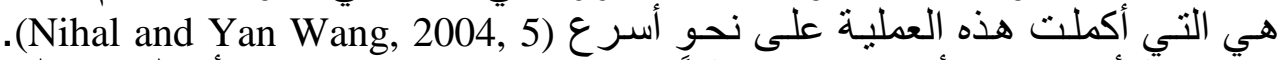

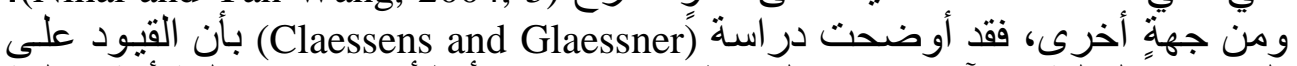
الثركات المالية في آسيا قد قاد إلى تطور مؤسساتي أبطأ وخدمات مالية أكثر كلفة لفية

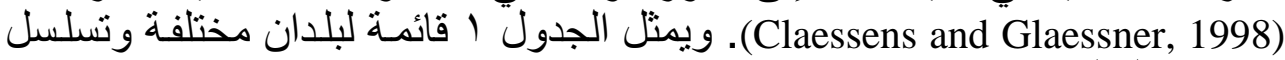

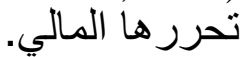

تسلسل التحرر المالي لعدد من البلدان المختلفة




\begin{tabular}{|c|c|c|}
\hline $\begin{array}{c}\text { رأس المال أولال) } \\
\text { Capital Account First }\end{array}$ & $\begin{array}{c}\text { الأسواق المالية أولائ } \\
\text { Domestic Financial Market First }\end{array}$ & $\begin{array}{l}\text { أسواق الأسهر أولاق } \\
\text { Stock Market First } \\
\end{array}$ \\
\hline ف فiلند & الارجنتين & كندا كندا \\
\hline اليابان & 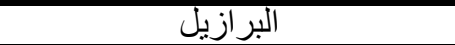 & الدانمارك \\
\hline المكسيك & كولومبيا & فرنسا \\
\hline الفلبين & أندونيسيا & ألمانيا \\
\hline تايلند & آيرلندا & هونك كونك (الصين) \\
\hline \multirow[t]{6}{*}{ فنززويلا } & كوريا الجنوبية & إيطاليا \\
\hline & النزرويج & ماليزيا - اليا \\
\hline & بيرو & البرتغال \\
\hline & تايو ان & إسبانيا \\
\hline & تركيا & المملكة المتحدة \\
\hline & & الو لايات المتحدة \\
\hline
\end{tabular}

Source: Nihal Bayraktor \& Yan Wang, 2004, Foreign Bank Entry Performance of Domestic Bank: The Sequence of Financial Liberalization, August, World Bank, P. 31.

ويمكن ومن خلال معطيات الجدول أن نستتتج بأن الخطوات الأولى في عملية

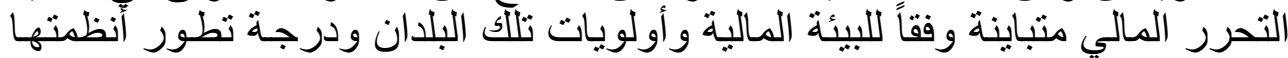

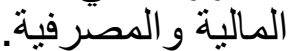

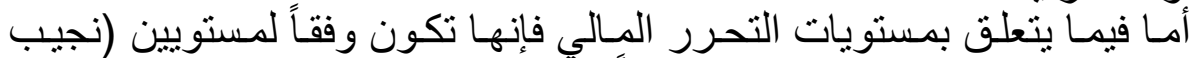

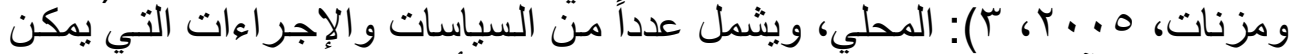

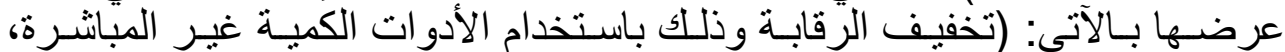

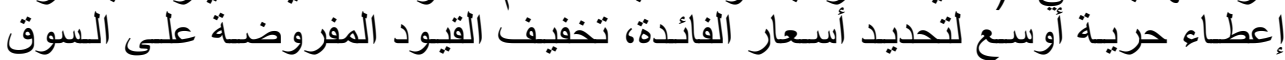

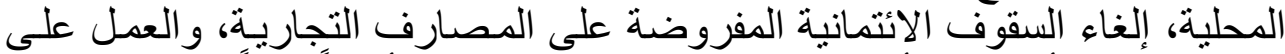
تطوير البنية الأساسية للأسواق المالية). الدولي، ويتضمن أيضاً عدداً من الإجراء الاتهات

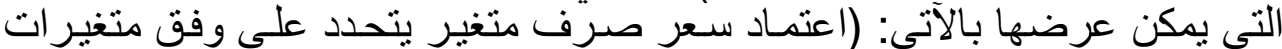

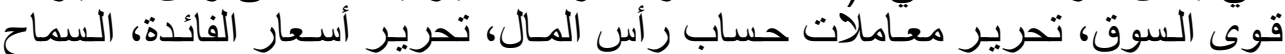

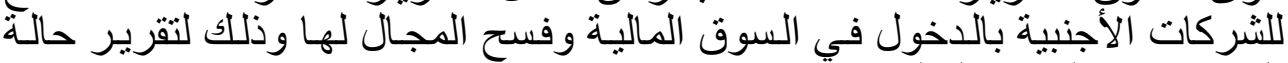
التنافسية في القطاع المالي).

\section{ثُالثاً المنافع والكلف المحتملة للتحرر المالي

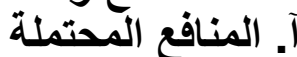

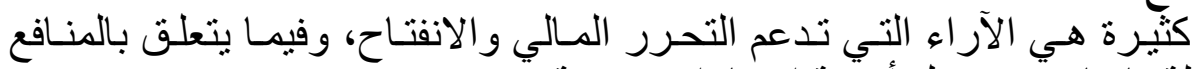
المحتملة فإنها تدور هول الأبر أبئة اعتبار ات رئيسة:

\section{1ـ الوصول إلى أسواق رأس المال العالمية}

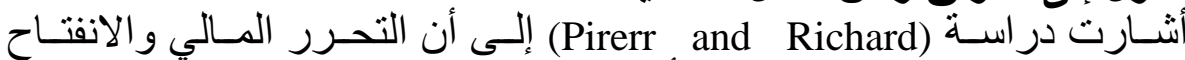

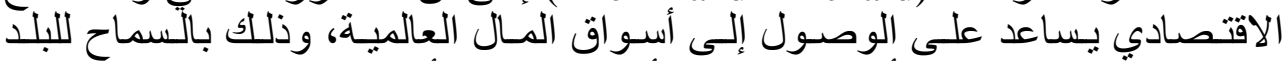
المعني بالأقتر اض في الأوقات السيئة كأوقات الكساد أو الأنحر الف الحساد في بنود لبات

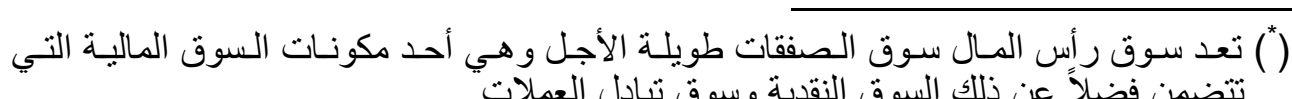


دكتور الشكرجي والطائي والنعيمي [rم1]

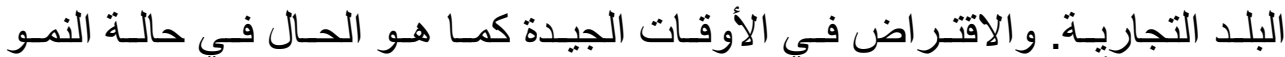

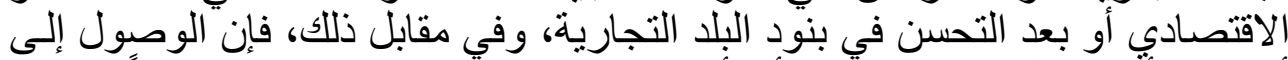

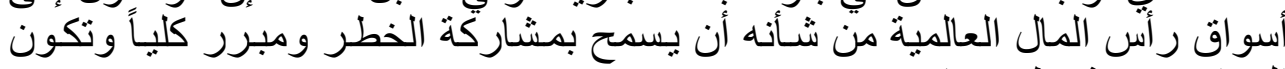

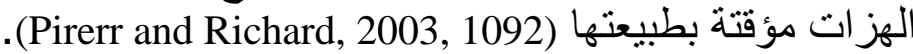

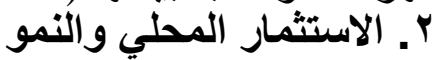

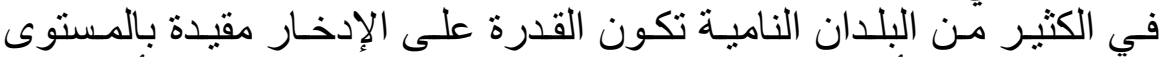

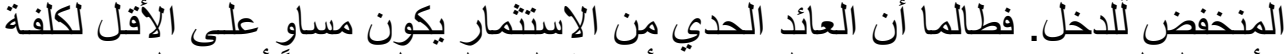

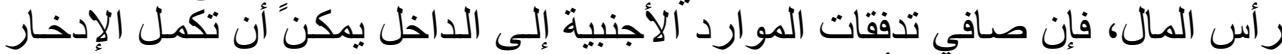

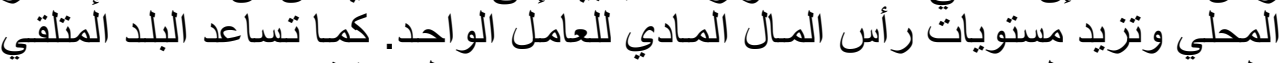

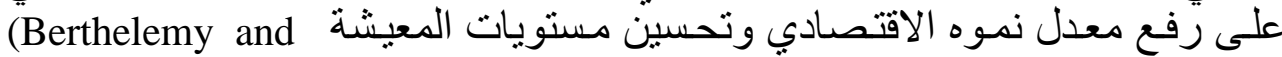

.Demurger, 2000, 140-150)

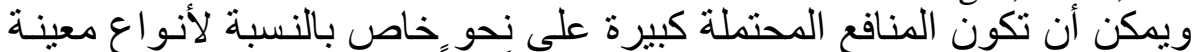

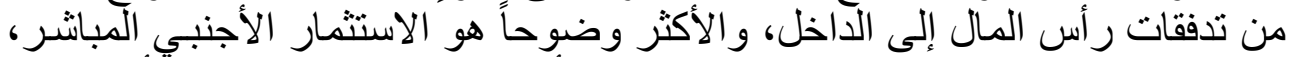

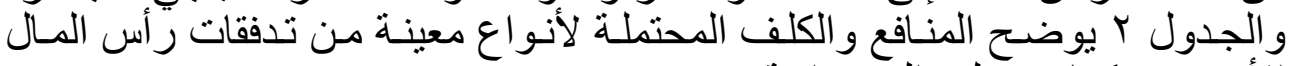
الأجنبي، وكما توصلت إليه دراسة (Helmut Risen and Marcelo, 2001).

\begin{tabular}{|c|c|c|c|c|c|}
\hline \multicolumn{6}{|c|}{ المنافع والكلف المحتملة لأنواع معينة من تدفقات رأس المال الأجنبي } \\
\hline \multicolumn{2}{|c|}{ ألكلف: } & \multicolumn{3}{|c|}{ المنافع } & \multirow[b]{2}{*}{ أنواع تدفقات رأس الأجنبي } \\
\hline 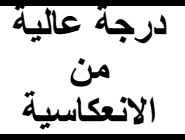 & الاتحر اقَمات & الاستهلاك & الكفاءة & الأسنثمار إلى & \\
\hline & $(\times)$ & $x$ & $x$ & $x$ & المباشر تنمار الاجنبـــي \\
\hline$x$ & $(x)$ & & $x$ & $(x)$ & استثمار أسهم المحفظة \\
\hline$x$ & $(x)$ & $x$ & $x$ & & تدفقات سند المحفظة \\
\hline & $x$ & & $(x)$ & $x$ & ألإجلــل اض الــدين طويـلـ \\
\hline$x$ & $x$ & $(\times)$ & $(\times)$ & & ألإجـل اضل الـــين قـــير \\
\hline
\end{tabular}

إذ إن الاستثمار الأجنبي المبانشر قد يسهل تمويل أو نشر الأسـاليب الإداريـة

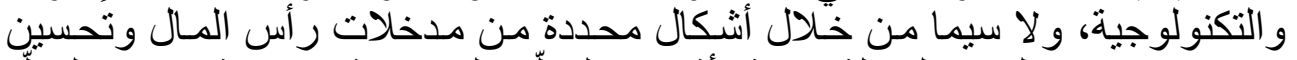

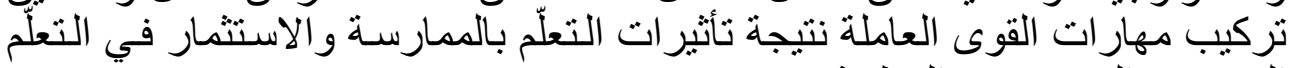

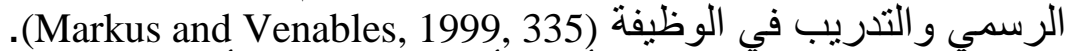

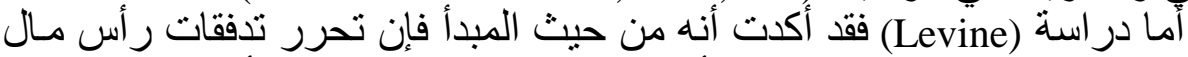

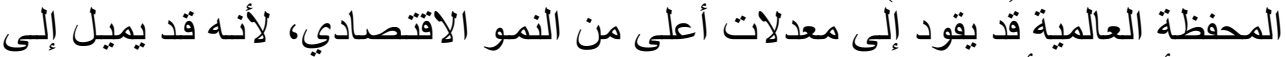

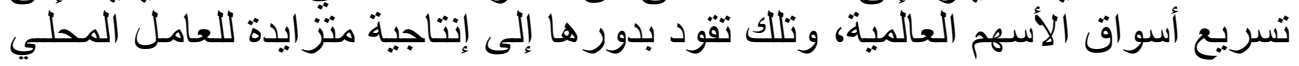
.(Levine, 1996, 75) 


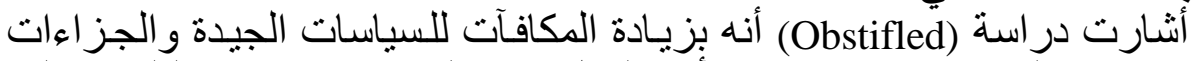

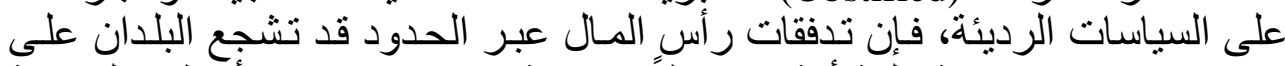

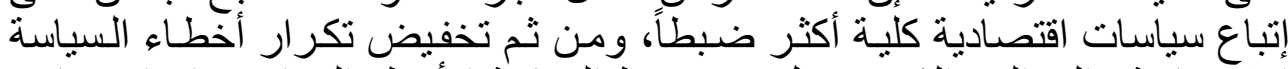

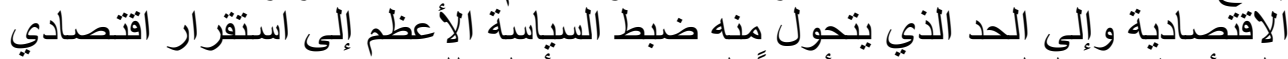

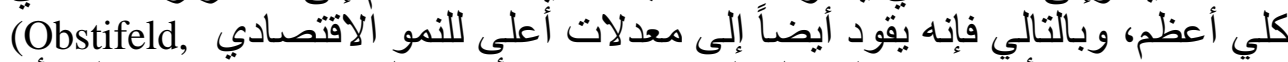

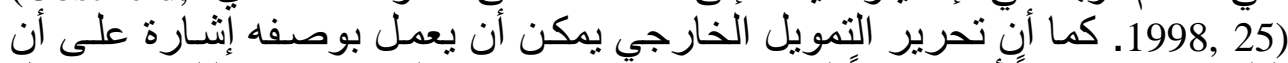

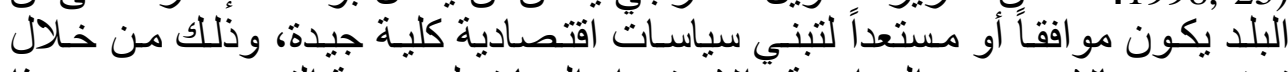

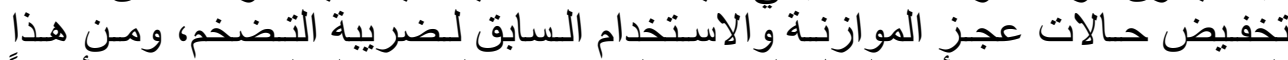

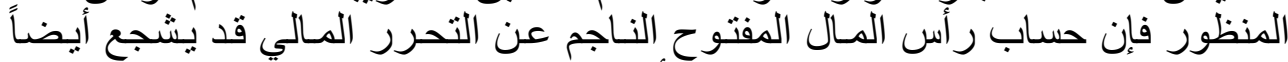

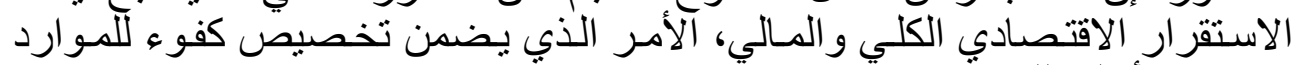
ومعدلات أعلى للنمو الاقتصادي (Pirerr-Richard, 2001, 1095).

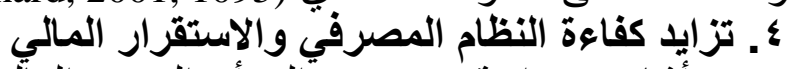

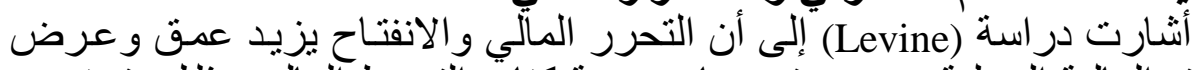

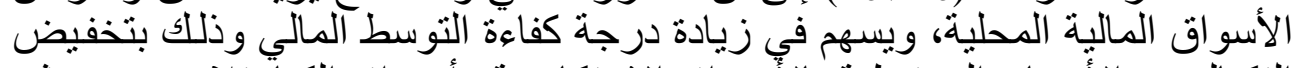

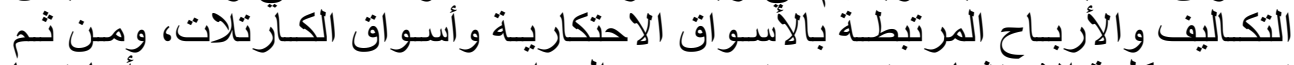

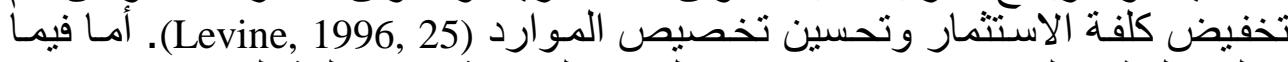
يتعلق بالقطاع المصرفي، فيمكن تحديد المنافع المتحققة من عملية التحرر والانفتاح

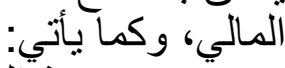

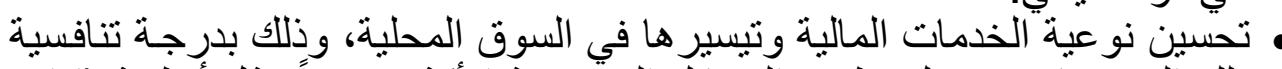

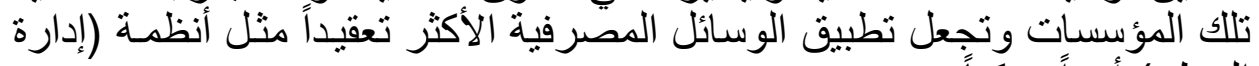
الخطر ) أمر اً ممكناً. • • تخدم لتحفيز التطوير و الإشر اف على المؤسسات المالية المحلية.

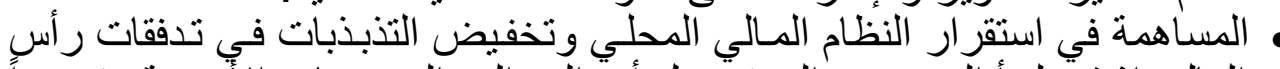

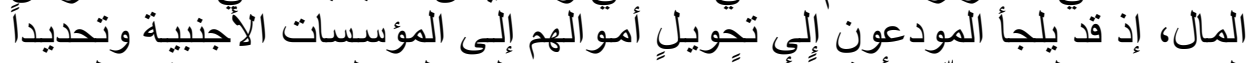

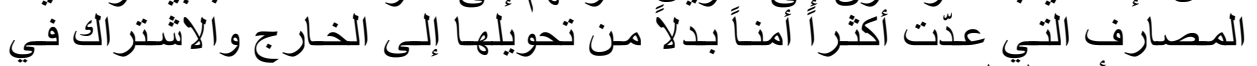

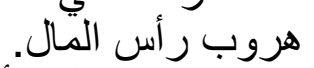

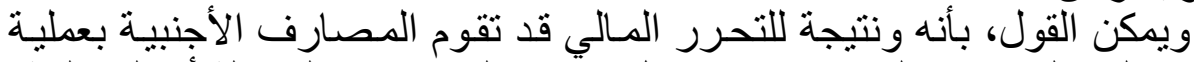

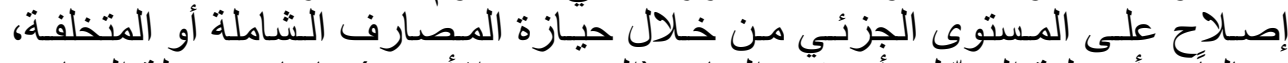

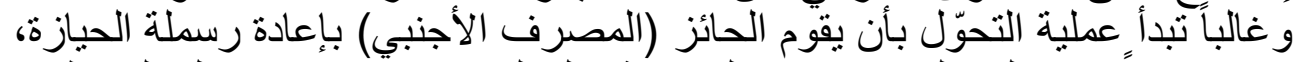

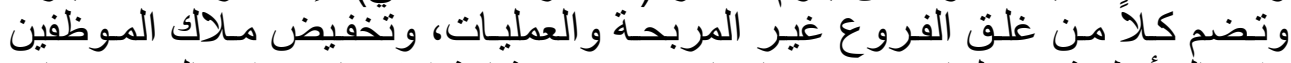

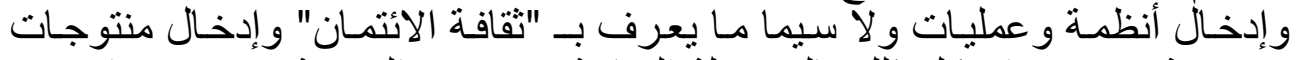
مصرفية جديدة، وإن كل ذلك بالمحصلة النهائية يعزز من الربحية ويسهم في إصلاح

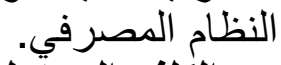

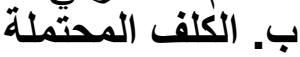

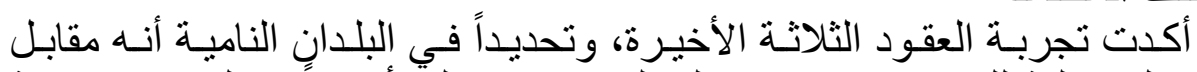

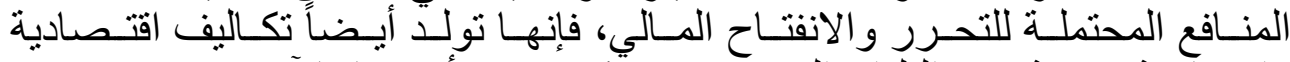
واجتماعية قد تؤثر في البلدان المتحررة، ويمكن تحديد أبرز ها بالآتي: ا ـ أتركز تدفقات رأس المال

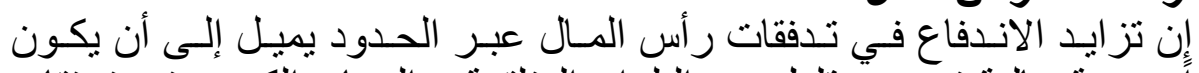

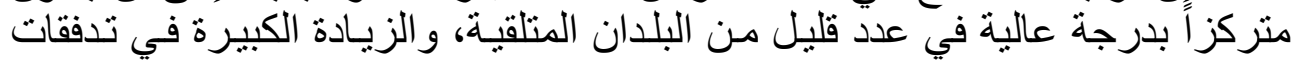


دكتور الشكرجي والطائي والنعيمي [10]

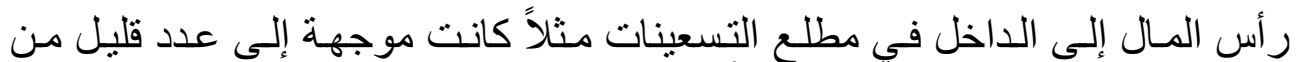

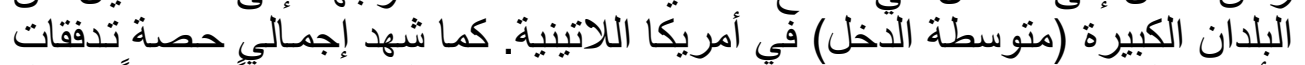

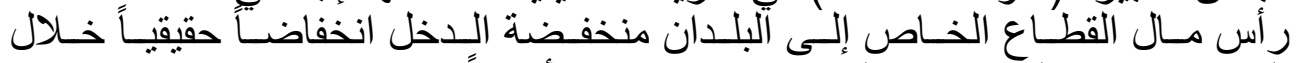

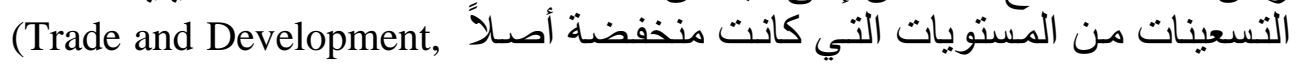

2002, 24-26)

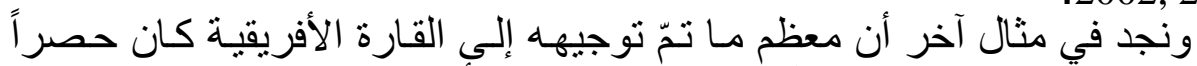

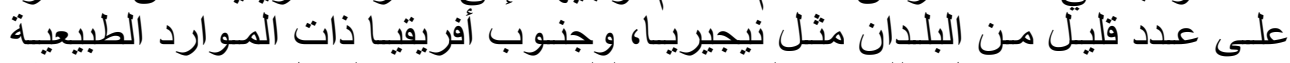

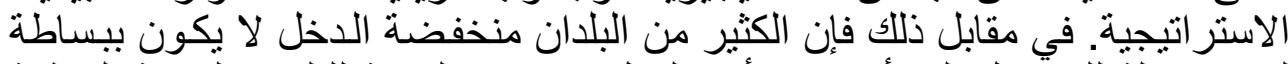

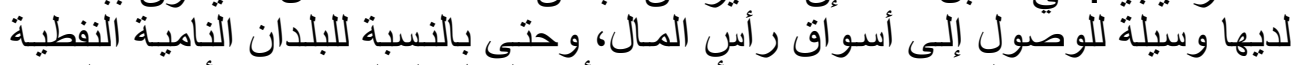

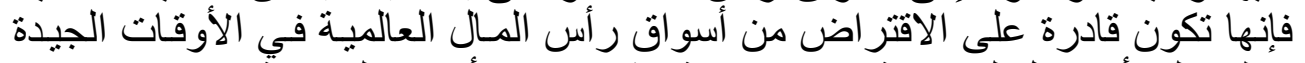

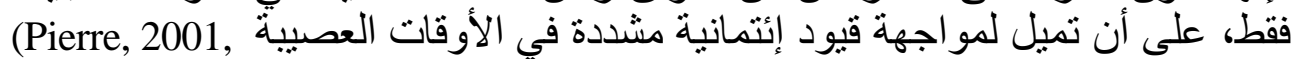

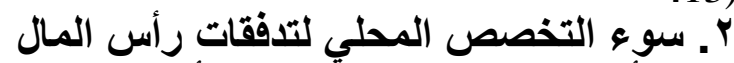

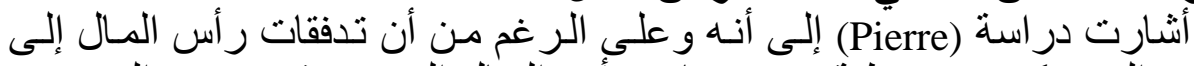

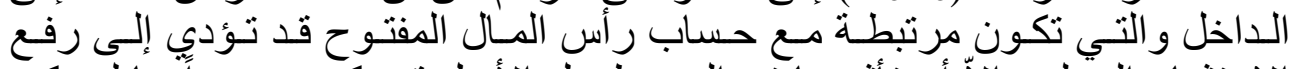

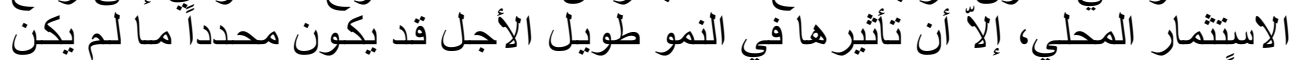

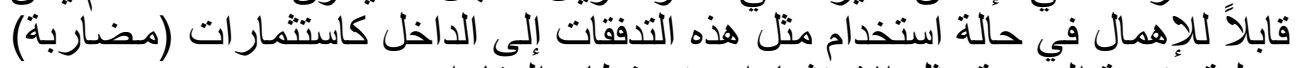

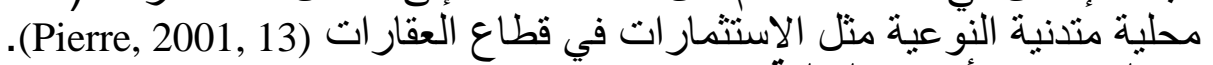

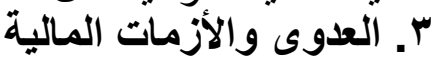

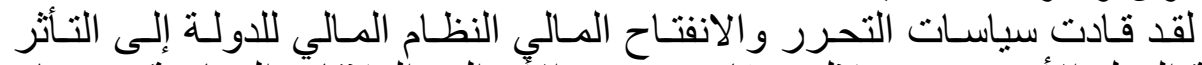

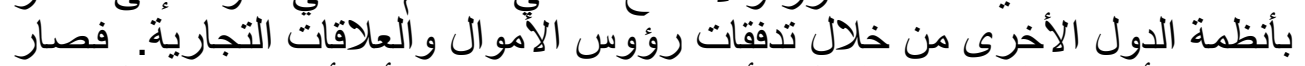

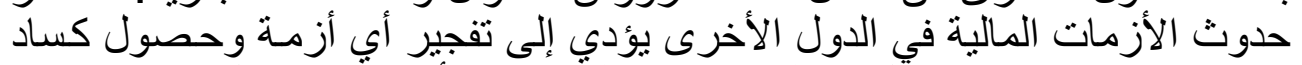

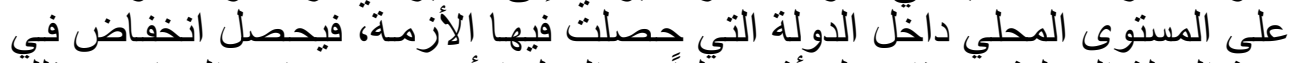

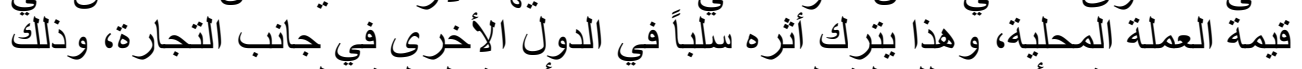

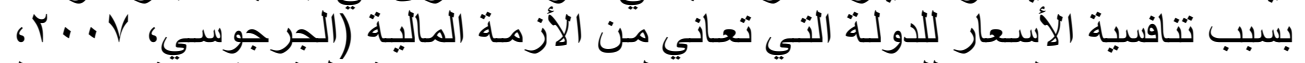

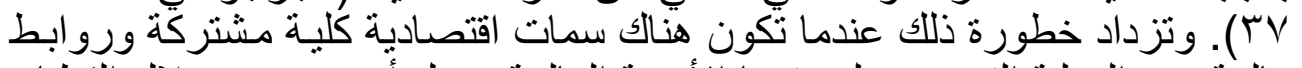

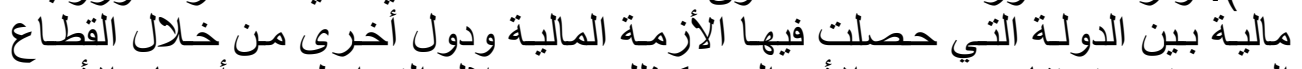

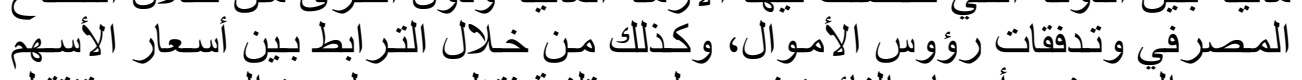

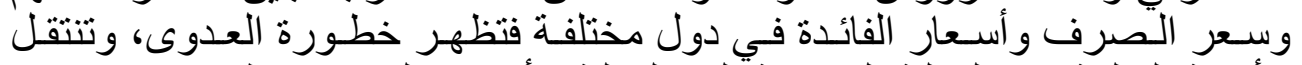

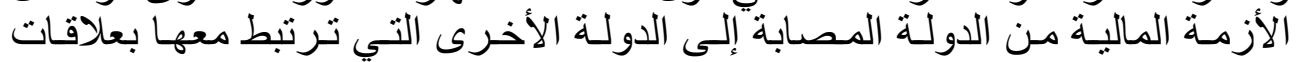

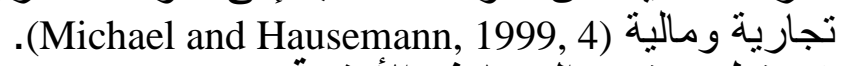
ع. خطر حضور المصارف روف الأجنبية

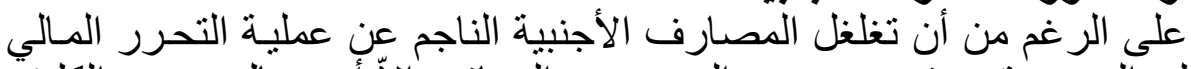

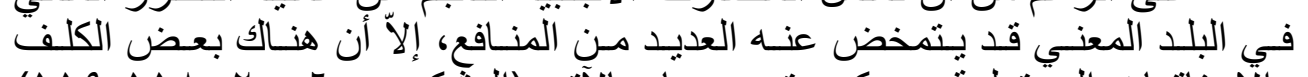

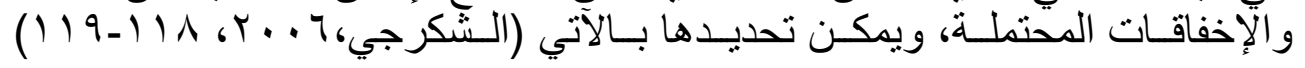
:(Nihal and Yah Wang, 2004, 4) • قد تزيد المصنارف الأجنبيـة الاضطر اب المـالي بالانسحاب المفاجئ أو بالعدوى

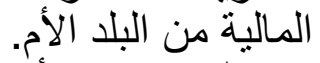

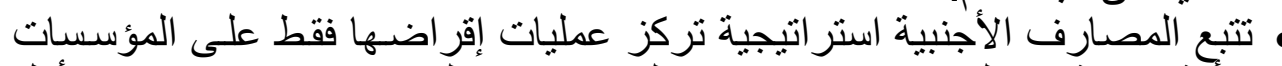

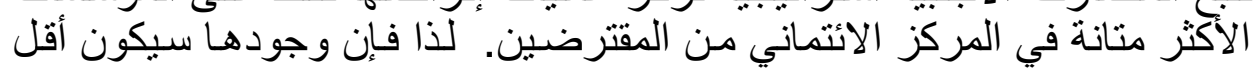


احتمالاً في المساهمة بالزيادة الثاملة في الكفاءة في القطاع المالي، وقد يكون لها

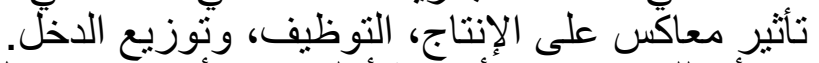

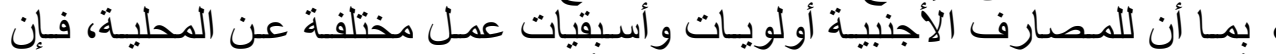

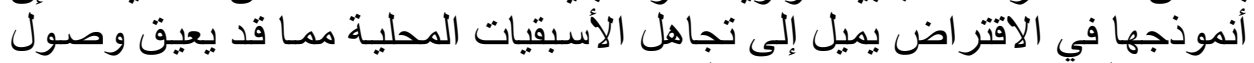

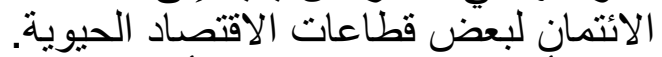

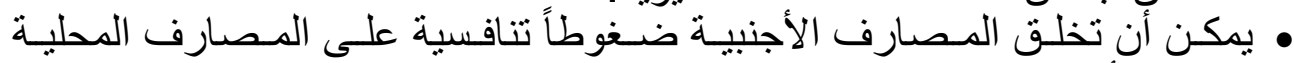

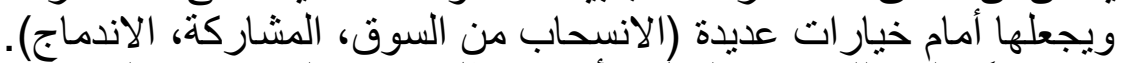

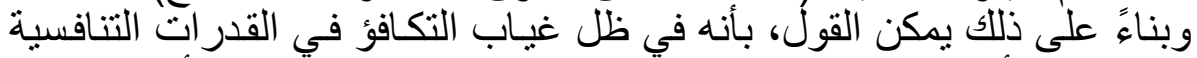

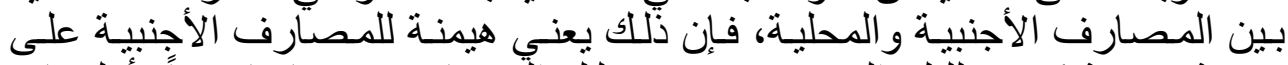

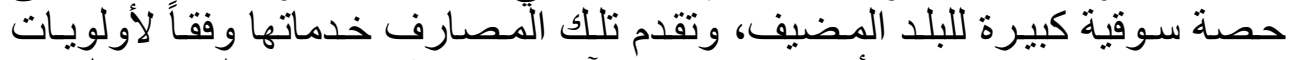

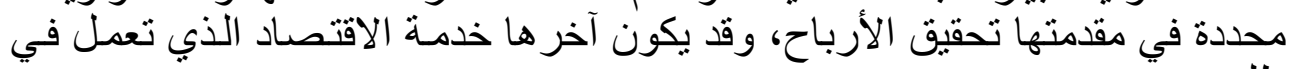

رابعاً. إصلاح النظام المالي وسرعته

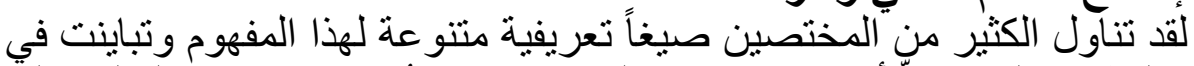

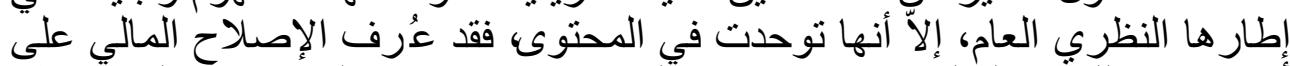

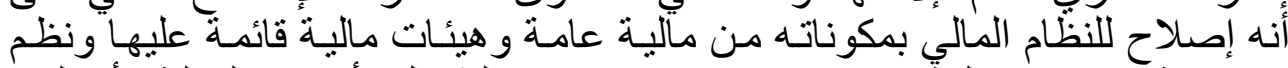

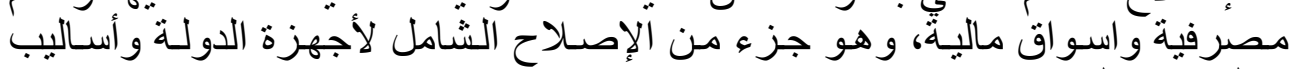

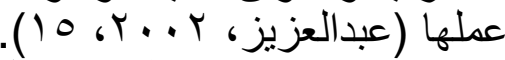

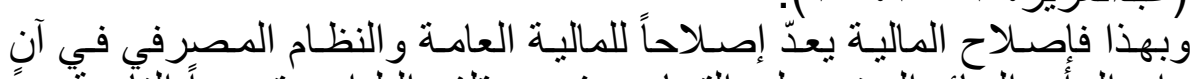

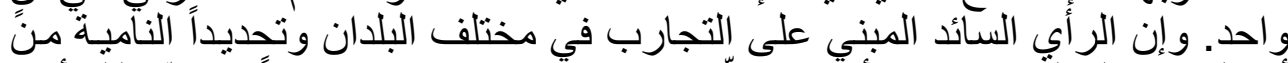

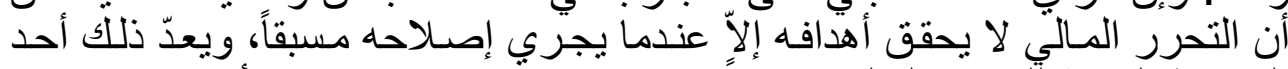

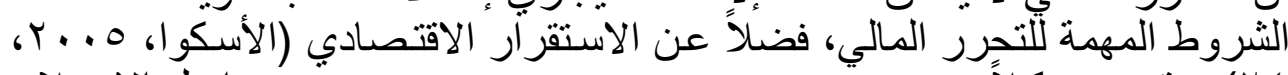

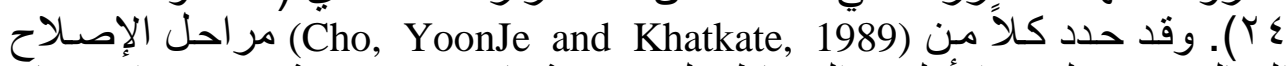

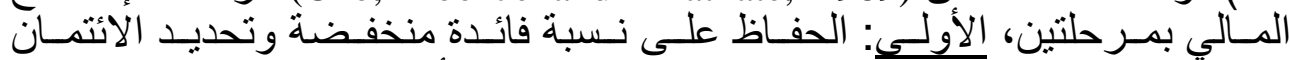

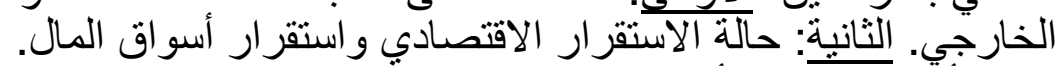

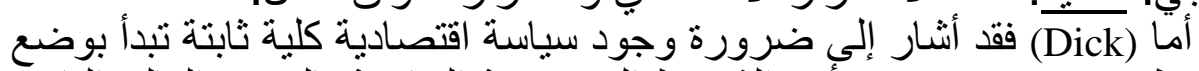

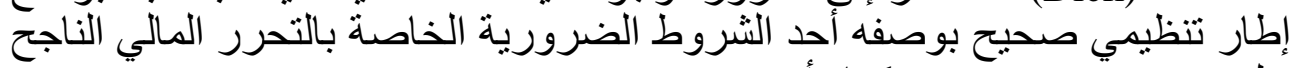

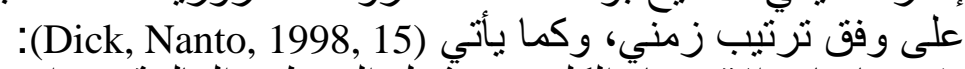

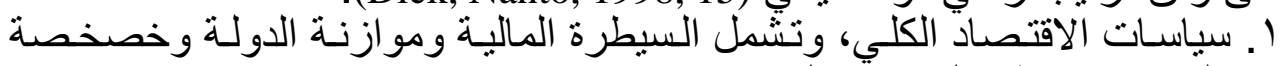

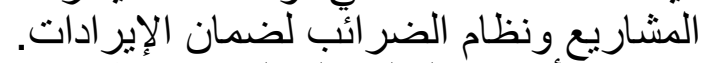

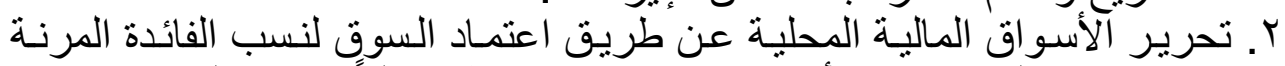

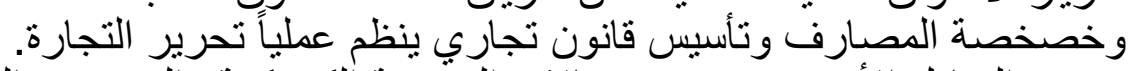

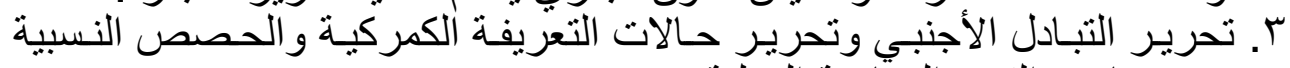
و غير ها من القيود التجارية الدئية الدولية.

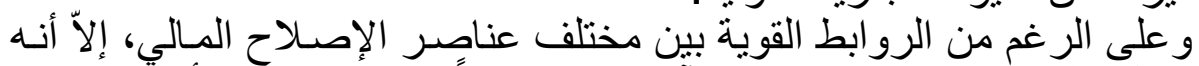

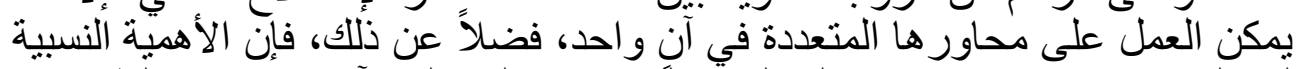

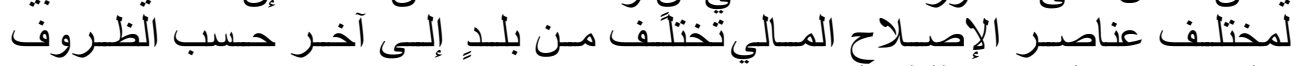

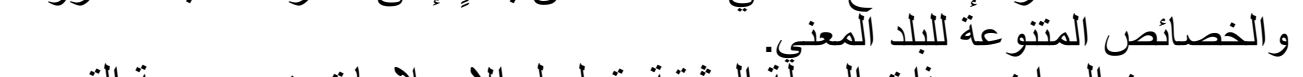

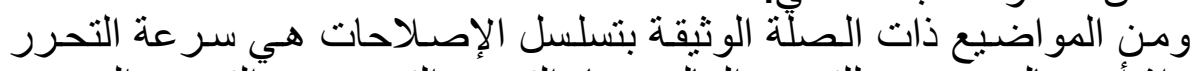

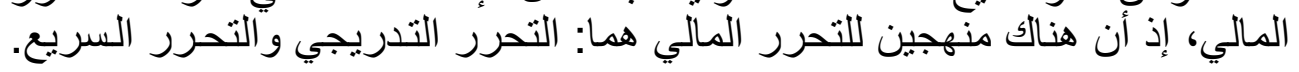


فالمنهجان لهما مخاطر هما وتكاليفهما، ويعتمد النهج التدريجي غالباً في الدول التي

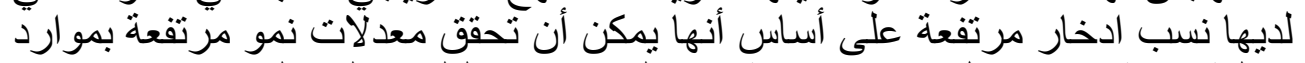

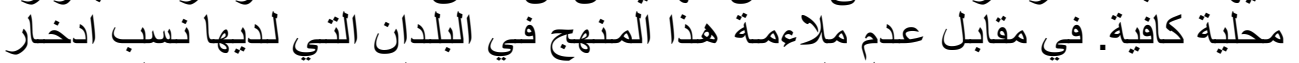

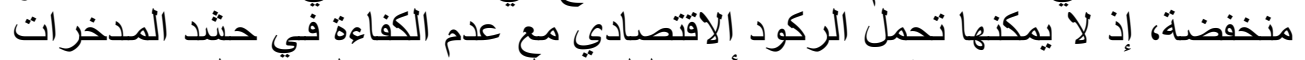

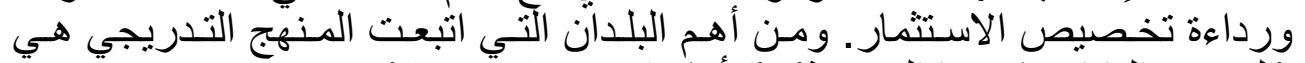

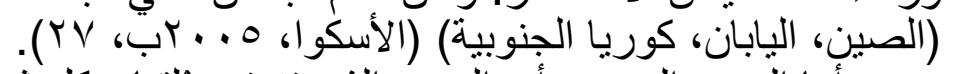

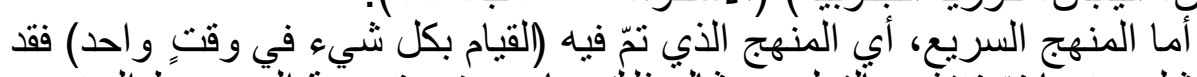

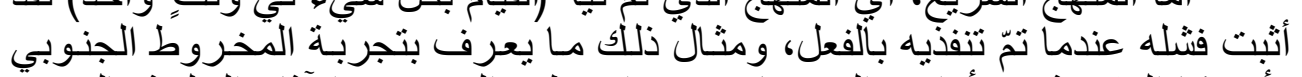

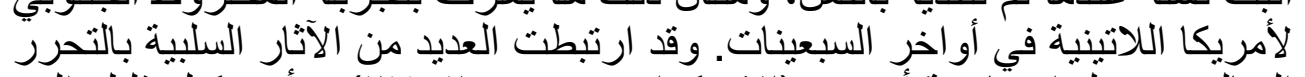

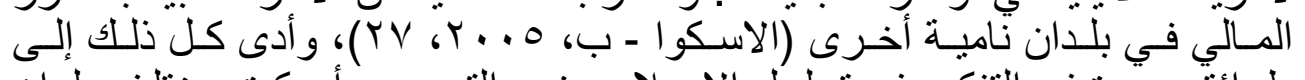

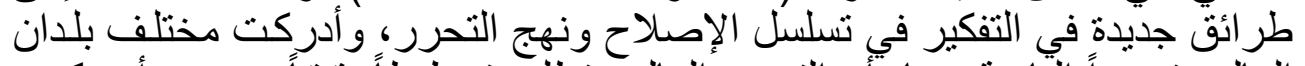

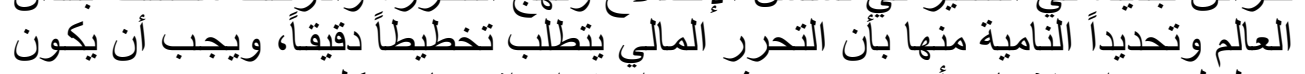

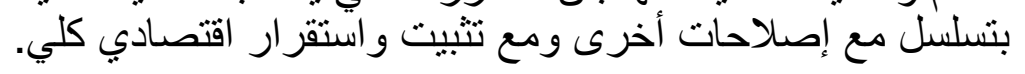

\section{الإصِلاح والتحرر المالي: تجربتا العراق ومصر

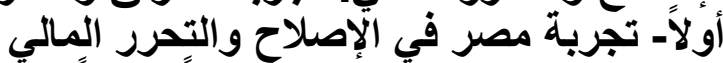

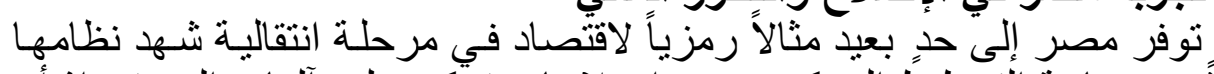

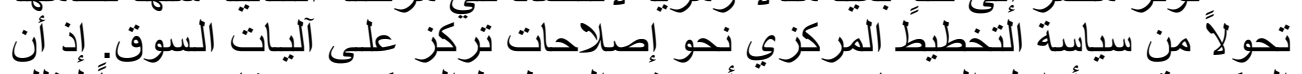

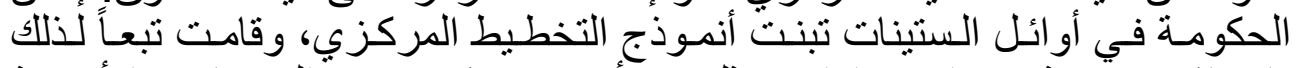

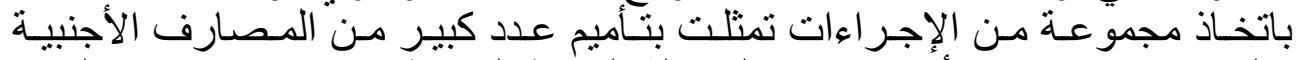

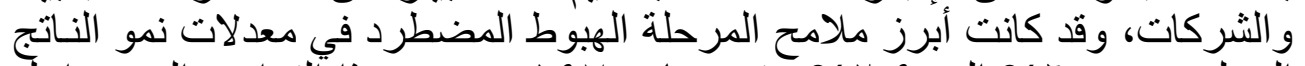

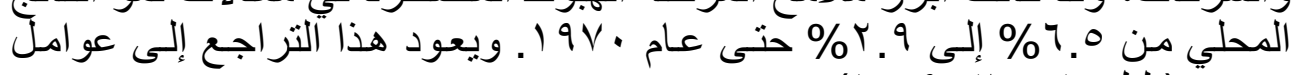

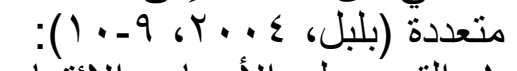
1. القيود على الأسعار و الاثتمان.

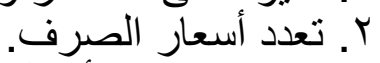
r. تردد رؤوس الأمو ال الأجنبية من التدفق إلى مصر.

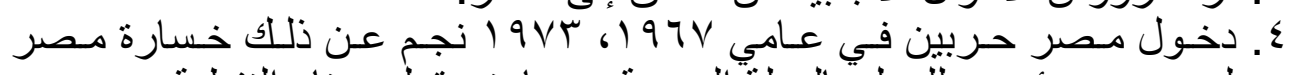

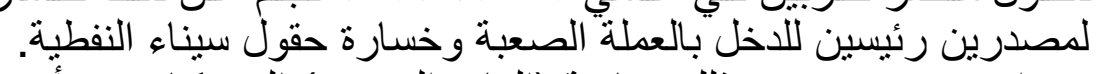
واعتمدت مصر بعد ذلك سياسـة (الباب المفتوح) التي كُّان من أبرز أهداء أهدافها

:(Eltony, 2003, 25)

1. استبدال ألدور الريادي للحكومة بالقطاع الخاص.

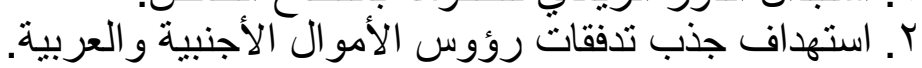

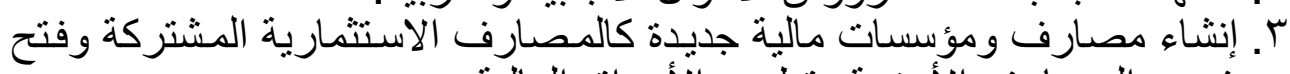

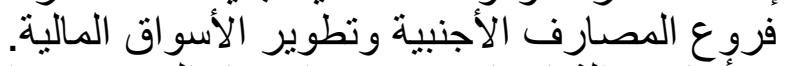

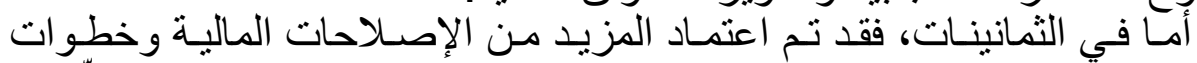

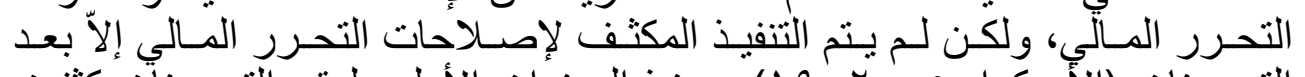

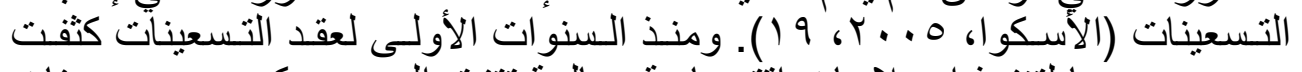

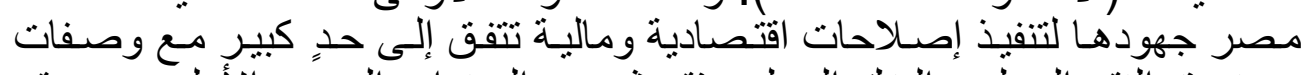

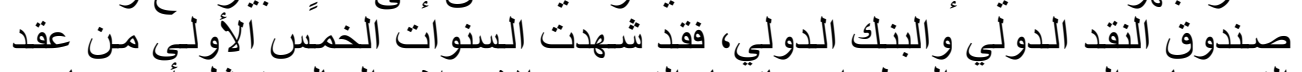

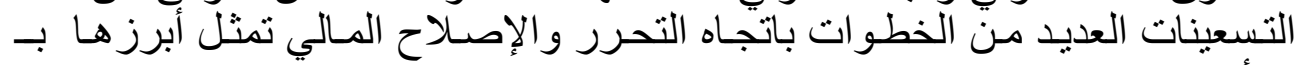

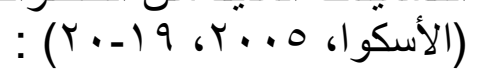


I إ. إعادة هيكلة المصارف و القطاع المالي.

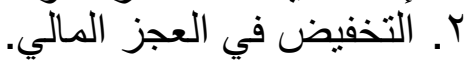

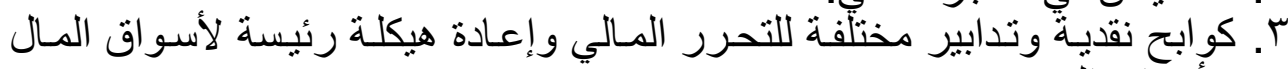

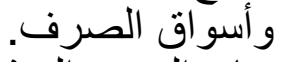

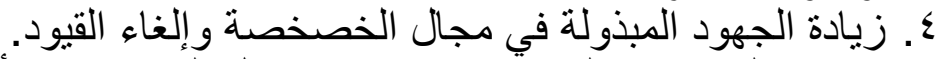

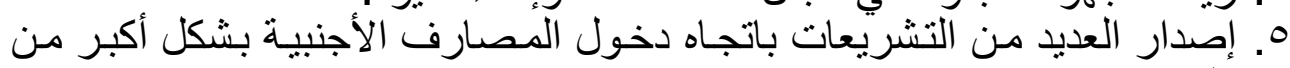

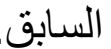

إن تللك الخطوات كان لها آثار هـا الإيجابيـة على مجمل الحيـاة الاقتصادية في

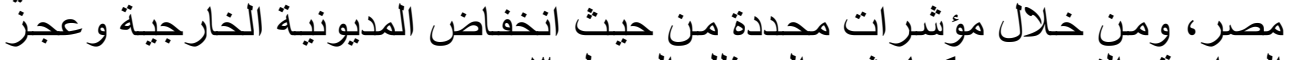

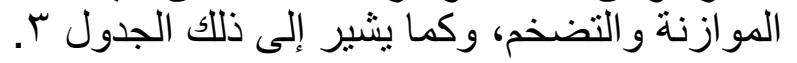

\begin{tabular}{|c|c|c|}
\hline \multicolumn{3}{|c|}{ الآثار الإيجابية للإصلاح والتحرر المالي لمؤشرات اقتصادية مختارة } \\
\hline \multicolumn{2}{|c|}{ فَتزرة الإصلاح والتحرر المالي } & \multirow{2}{*}{ المؤشرات } \\
\hline$r+.0 .199$ & $1919-197$. & \\
\hline$\%$ \%^ & $\% 101$ & الدين الخارجي إلى الناتج المحلي \\
\hline$\% 0 . V$ & $\%$ \%. & عجز الموازنة من الناتج المحلي \\
\hline$\%$ \%. & $\%$ \% & نسبة التضخم من الناتج المحلي \\
\hline 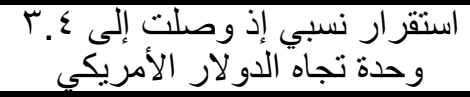 & 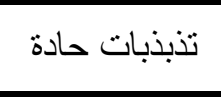 & سعر صرف الجنيه المصري \\
\hline
\end{tabular}

Source: Central Bank of Egypt, 1992-2005.

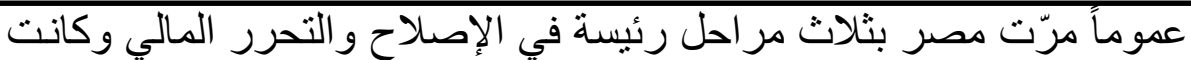

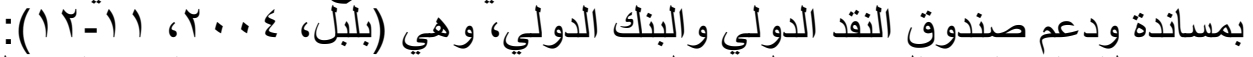

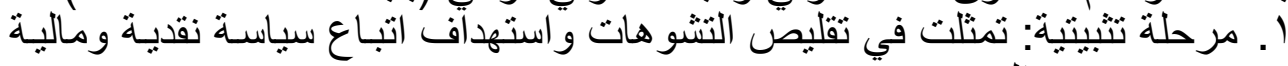

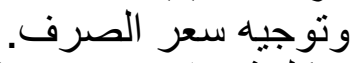

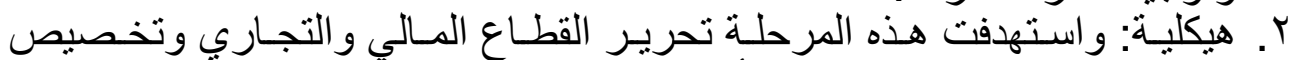

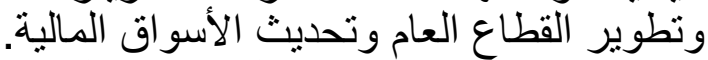

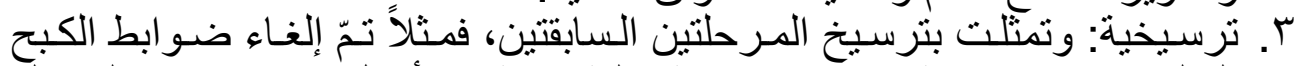

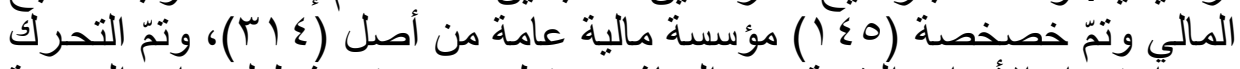

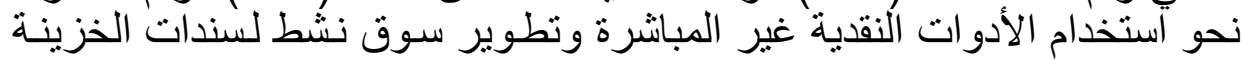
لضبط المصارف و الائتمان.

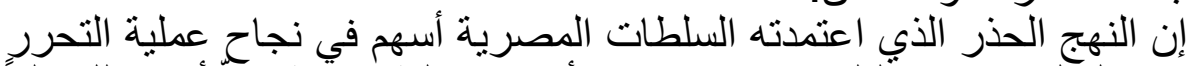

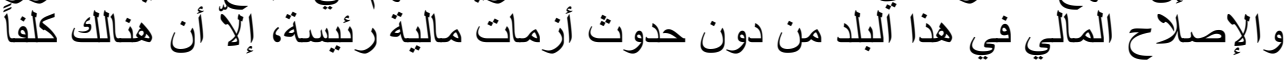

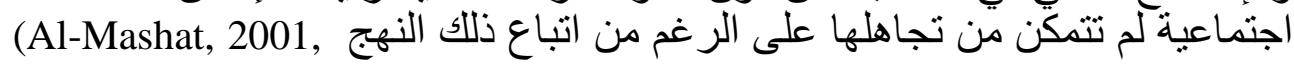

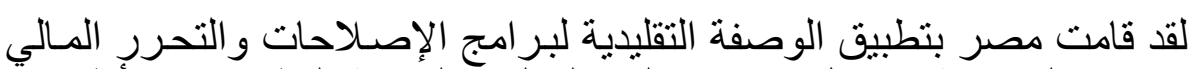

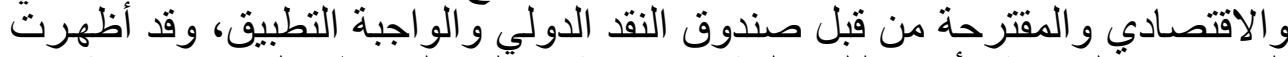

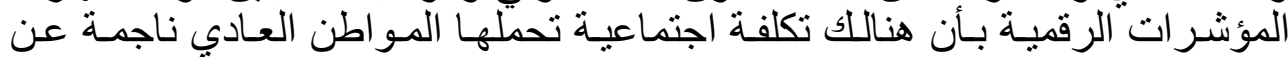

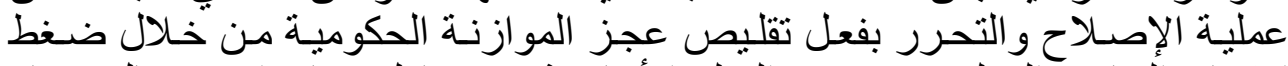

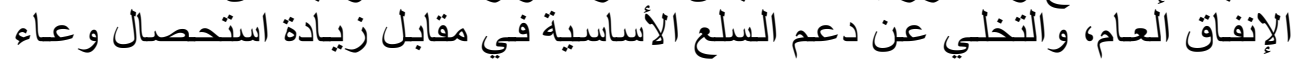


دكتور الشكرجي والطائي والنعيمي [1 199

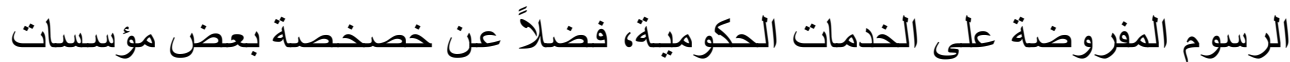

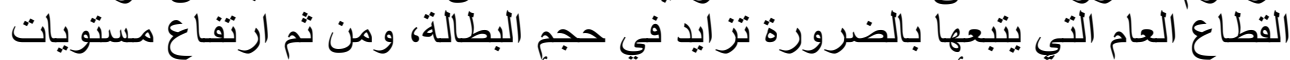

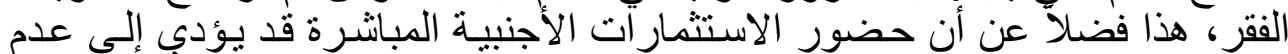

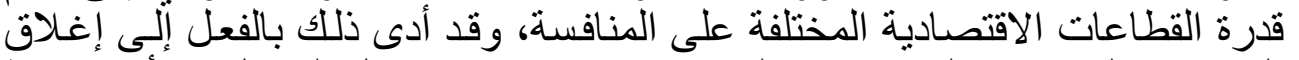

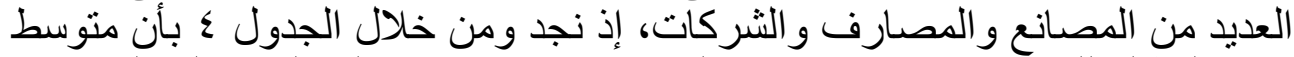

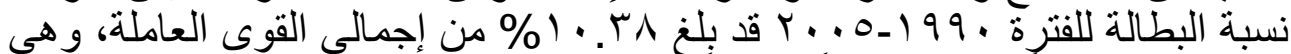

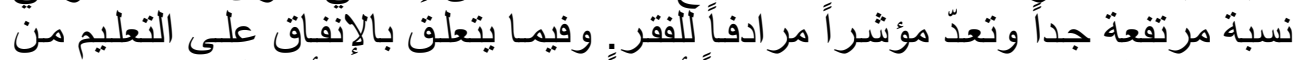

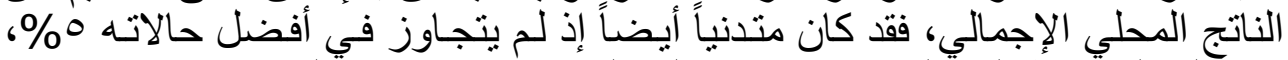

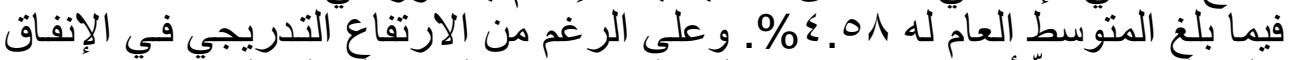

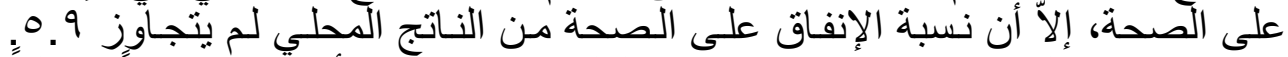

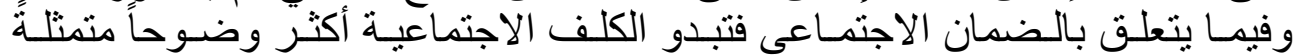
بالإنخفاض التدريجي على هذا البند ذو الأهمية الاجتماعية الكبيرة.

\begin{tabular}{|c|c|c|c|c|}
\hline \multicolumn{5}{|c|}{ مؤشرات الكلف الاجتماعية في مصرل ع } \\
\hline 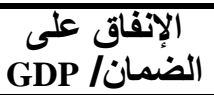 & الصحةثاق على الإنفاق & 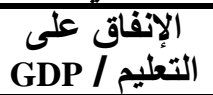 & إلى عدد البكانة & السنوات المؤشرات \\
\hline T.Y & & r.9 & $9 . r$ & 199 \\
\hline r. & & $\varepsilon .1$ & $1 \cdot .7$ & 1991 \\
\hline T.ร & & $\xi . Y$ & 9.1 & 1994 \\
\hline r. & & $\varepsilon .0$ & T.T & 1994 \\
\hline$r . \lambda$ & & $\varepsilon .7$ & T. & 1998 \\
\hline$\xi$. & T.V & $\varepsilon . V$ & 14.0 & 1990 \\
\hline .1 & r. & $\varepsilon . \wedge$ & TY. & 1997 \\
\hline .1 & r.9 & $\varepsilon .9$ & $9 . r$ & $199 \mathrm{~V}$ \\
\hline 1.1 & 0 & $\varepsilon . \lambda$ & 1.9 & 1991 \\
\hline$\cdot . \varepsilon$ & $\varepsilon .9$ & $\varepsilon . \lambda$ & $\Lambda . \Lambda$ & 1999 \\
\hline$\cdot r$ & $0 . Y$ & $\varepsilon .9$ & 9.7 & $r \ldots$ \\
\hline$\cdot Y$ & 0.5 & 0. & 1.1 & $r \cdot .1$ \\
\hline$\cdot Y$ & 0.9 & 0.1 & 11.1 & $r \ldots r$ \\
\hline$\cdot Y$ & 0.1 & $\varepsilon . \Lambda$ & $1 .$. & $r \cdot r^{\prime}$ \\
\hline$\cdot Y$ & $0 . \mathrm{V}$ & $\xi .1$ & $1 \cdot$. & $r \ldots \varepsilon$ \\
\hline$\cdot Y$ & 0.1 & $\varepsilon . V$ & 9.7 & $r \ldots o$ \\
\hline 1.5 & $0 . .9$ & $\varepsilon .01$ & $1 . \mu$ & المتوسط \\
\hline
\end{tabular}

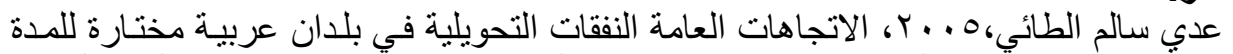

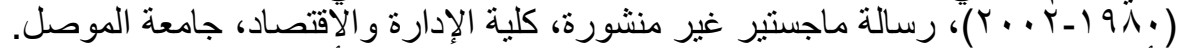

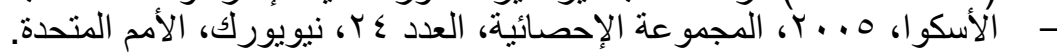

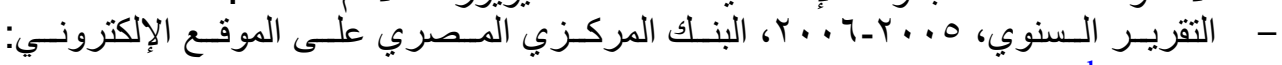

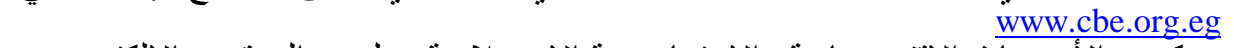

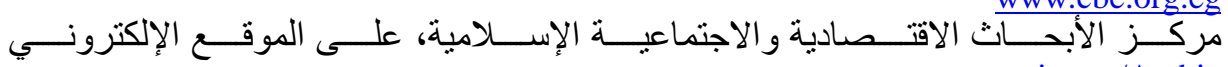
www.sesrtcic.org/Arabic 
The World Health Report, 2000-2006, World Health Organization, On Website: www.who.int.

$$
\text { * لم تتوفر بيانات في تللك السنوات ولهذا لم يظهر حجم الإنفاق في الجدول. }
$$

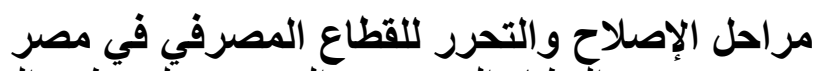

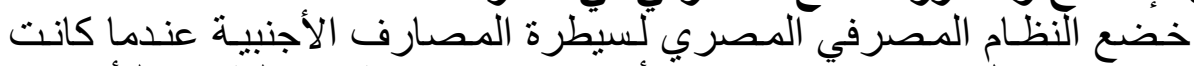

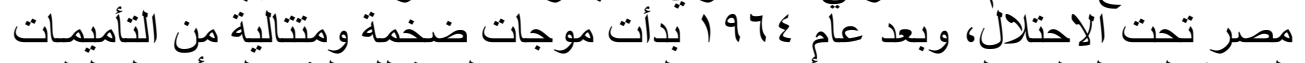

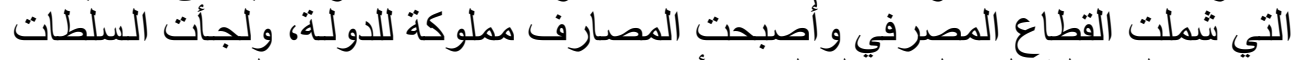

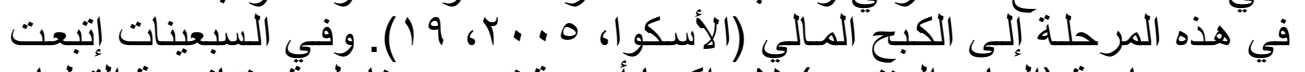

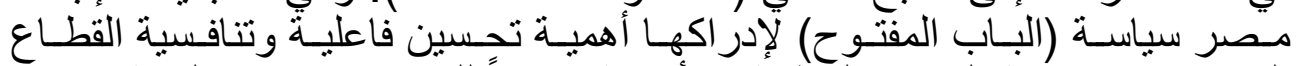

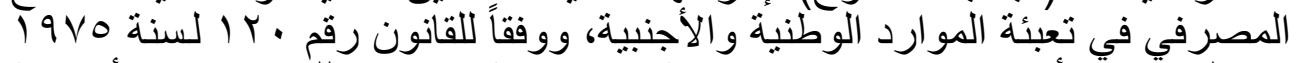

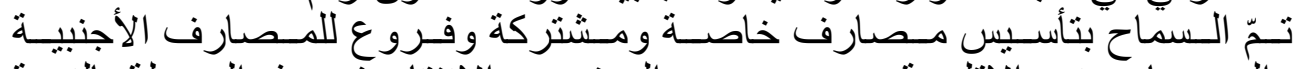

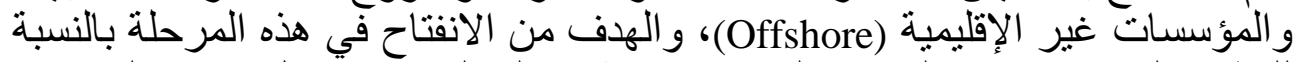

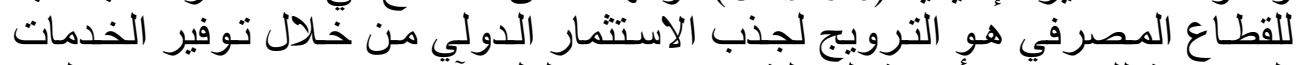

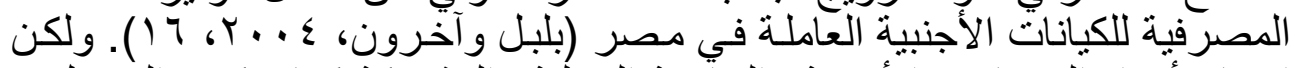

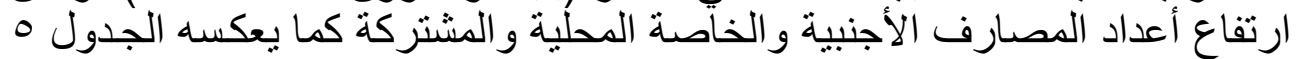

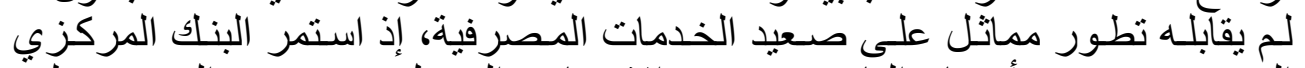

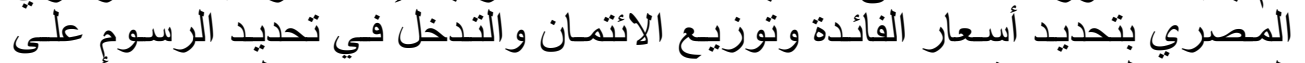

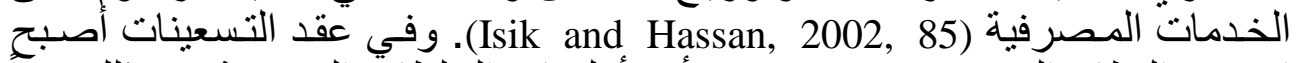

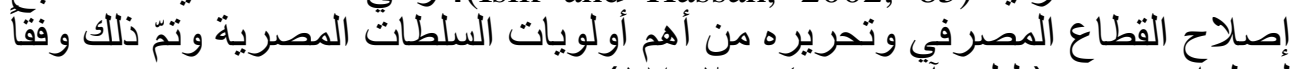

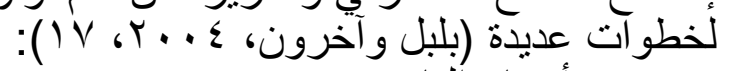
- تحرير أسعار الفائدة.

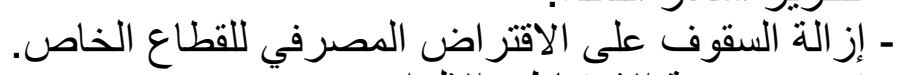

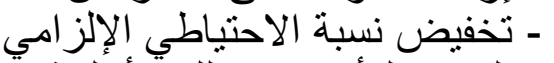

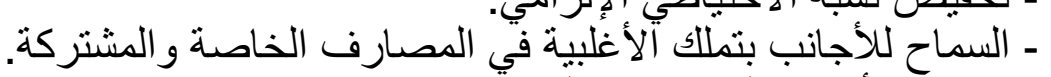

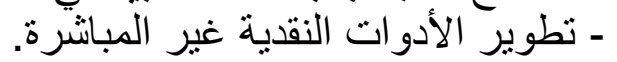

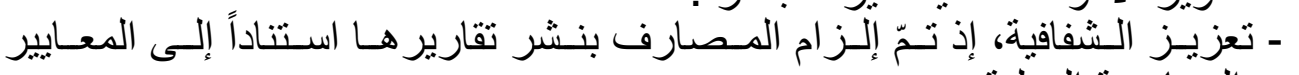
الأحاسبية الدولية (IAS).

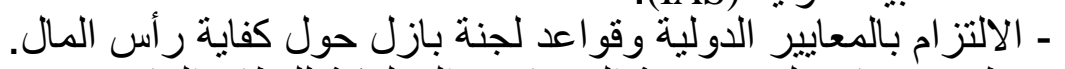

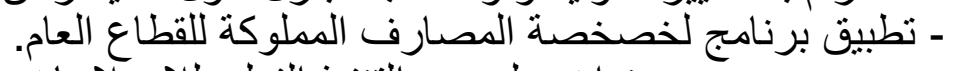

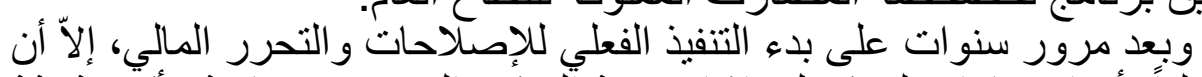

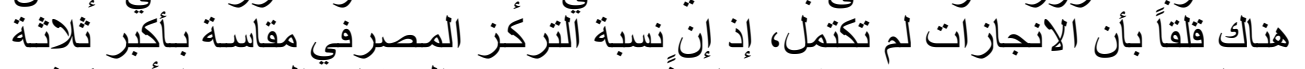

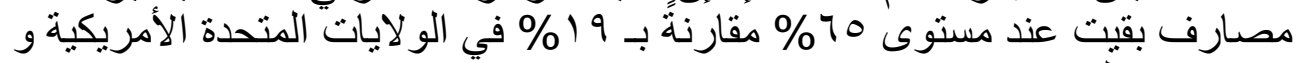

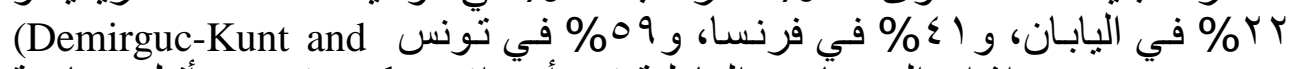

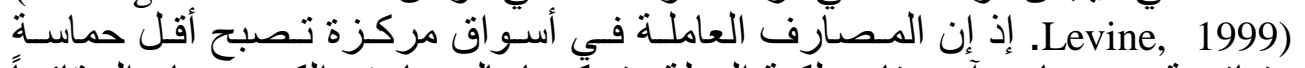

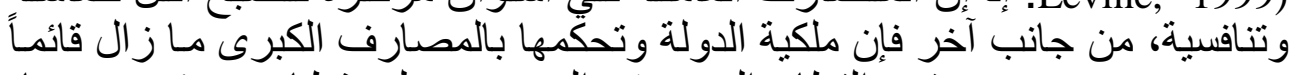

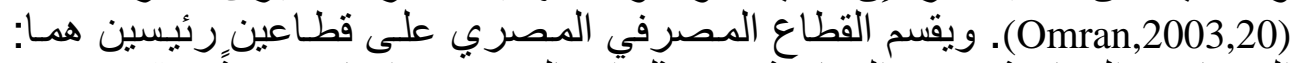

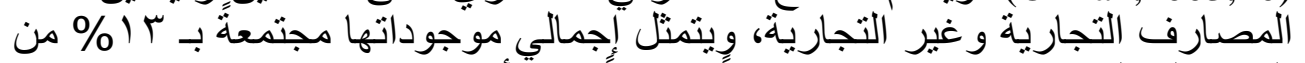

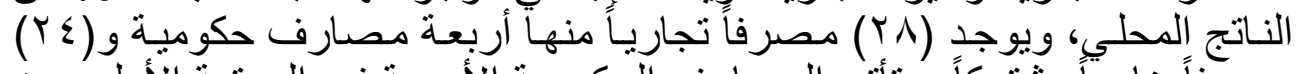

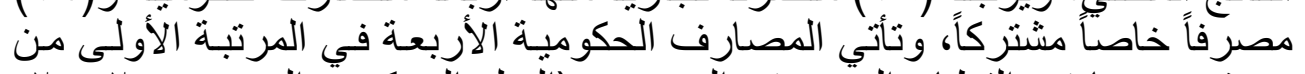

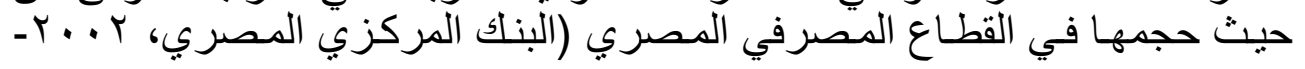




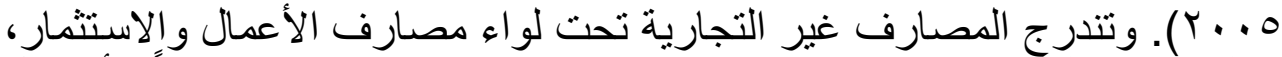

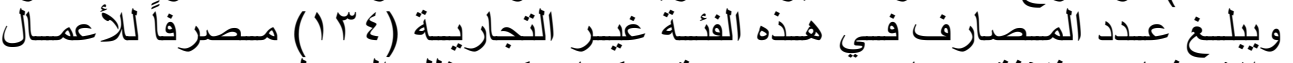

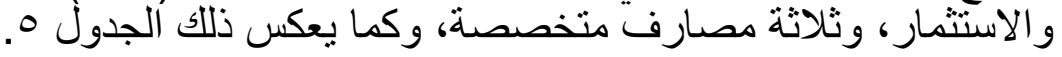

أسواق الأوراق المالية المصرية سلك تطور أسواق الأوراق المالية في مصر (القاهرة والإسكندرية) الدسار

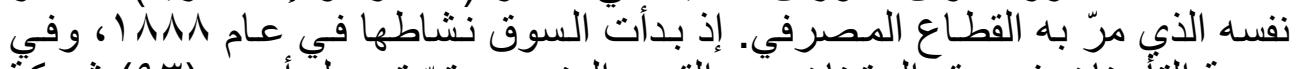

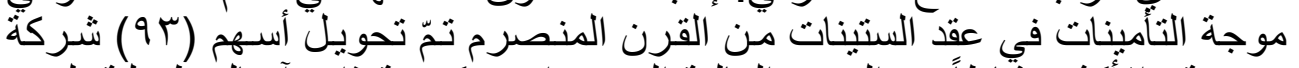

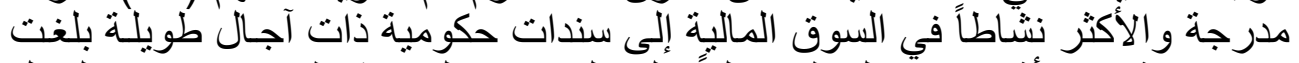

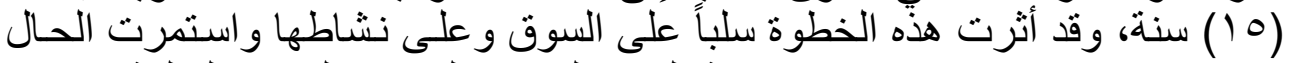

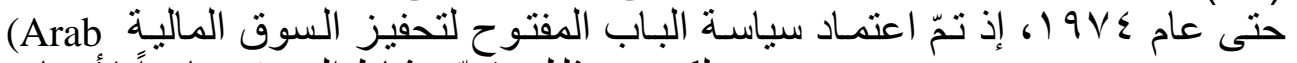

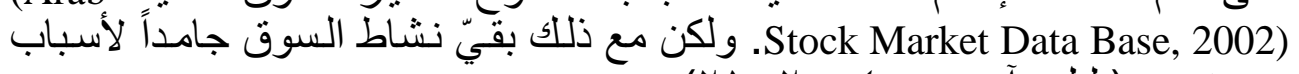

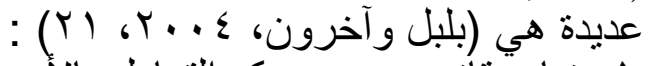

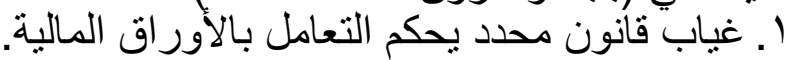

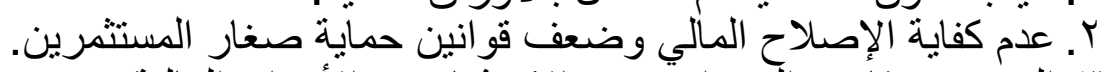

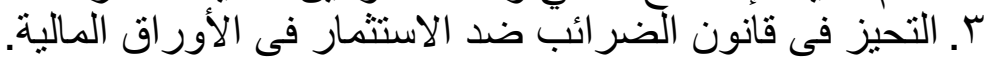

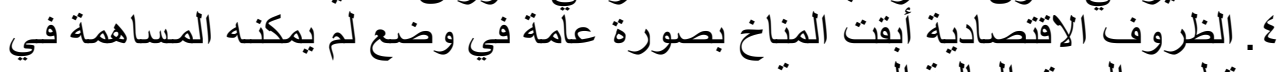
تطوير السوق المالية المصرية.

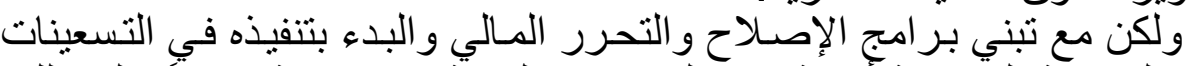

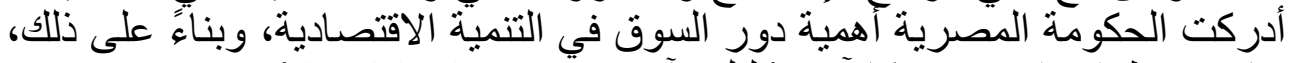

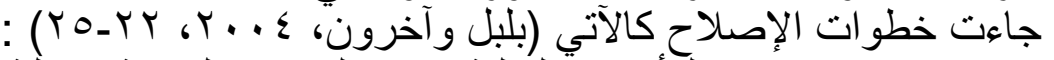

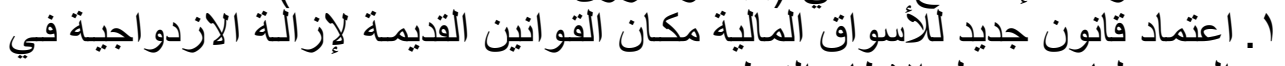

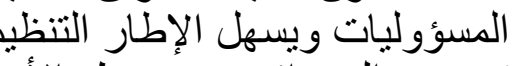

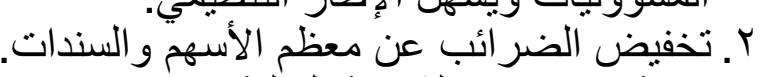
ك. ب. تقوية الإفصاح و الثفافية المالية.

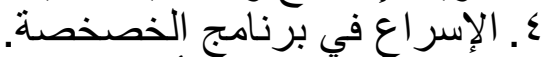

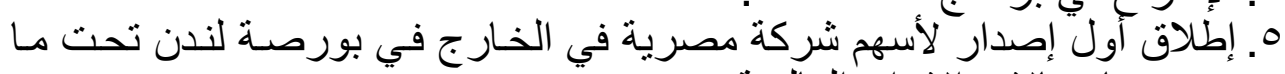
يعرف بإيصالات الإيداع العالمية (GDR).

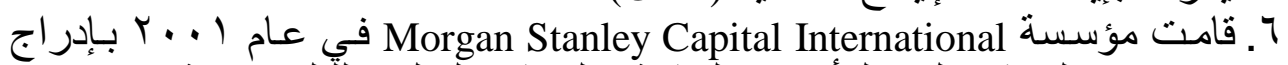

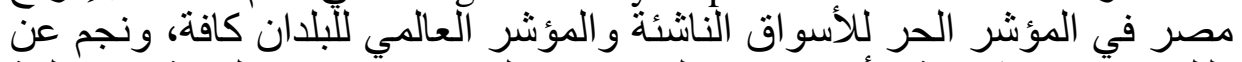

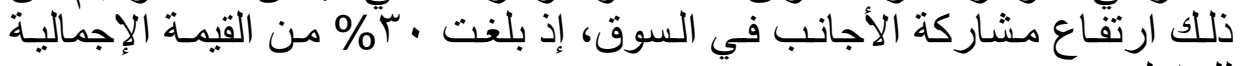

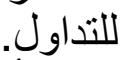
لقد أسهمت هذه التطور ات في إحداث توسع ملحوظ في حجم ونشاط السوق

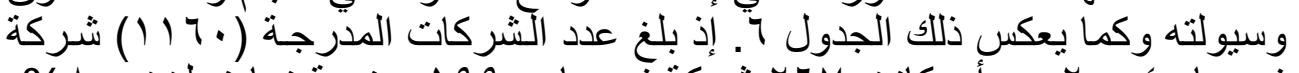

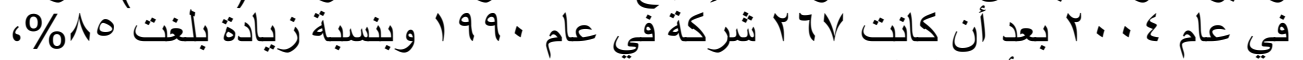

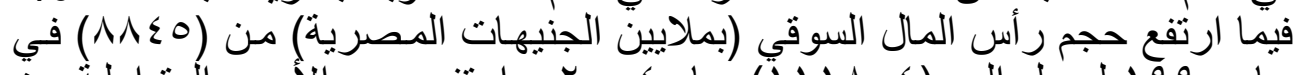

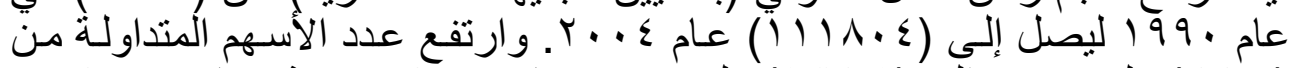

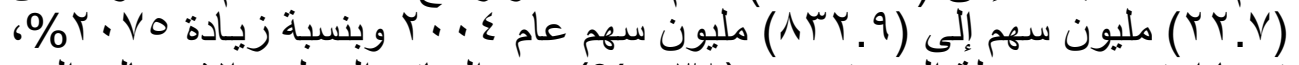

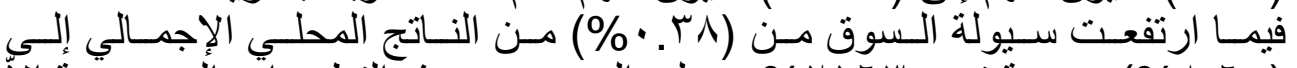

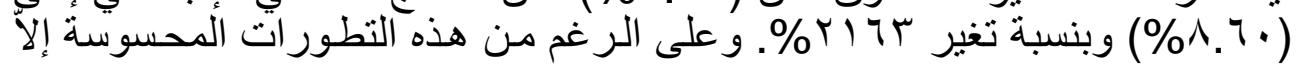


أن حقيقة الأسواق المالية في مصر علي الرغم من إجر اءات الإصـلاح لا تمثل آلية

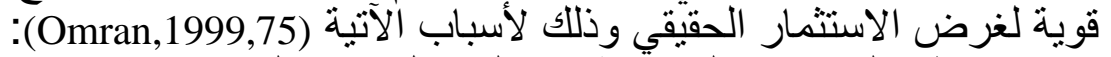

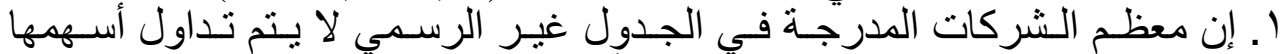

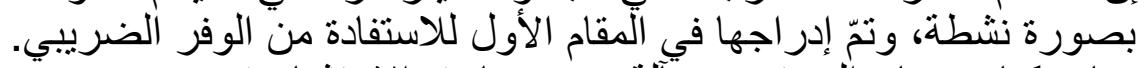

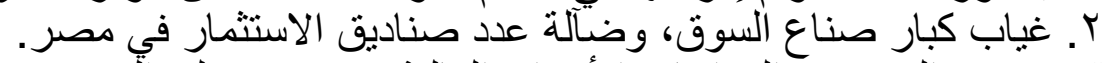

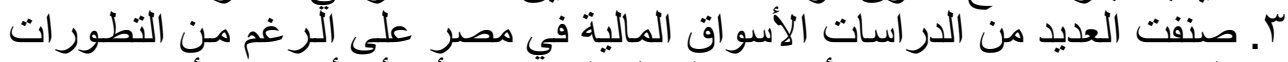

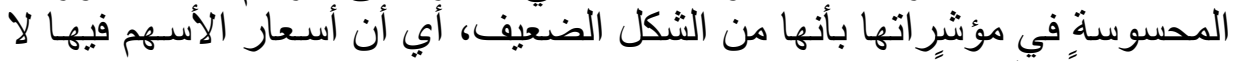
تتبع مسار أ عشو ائياً.

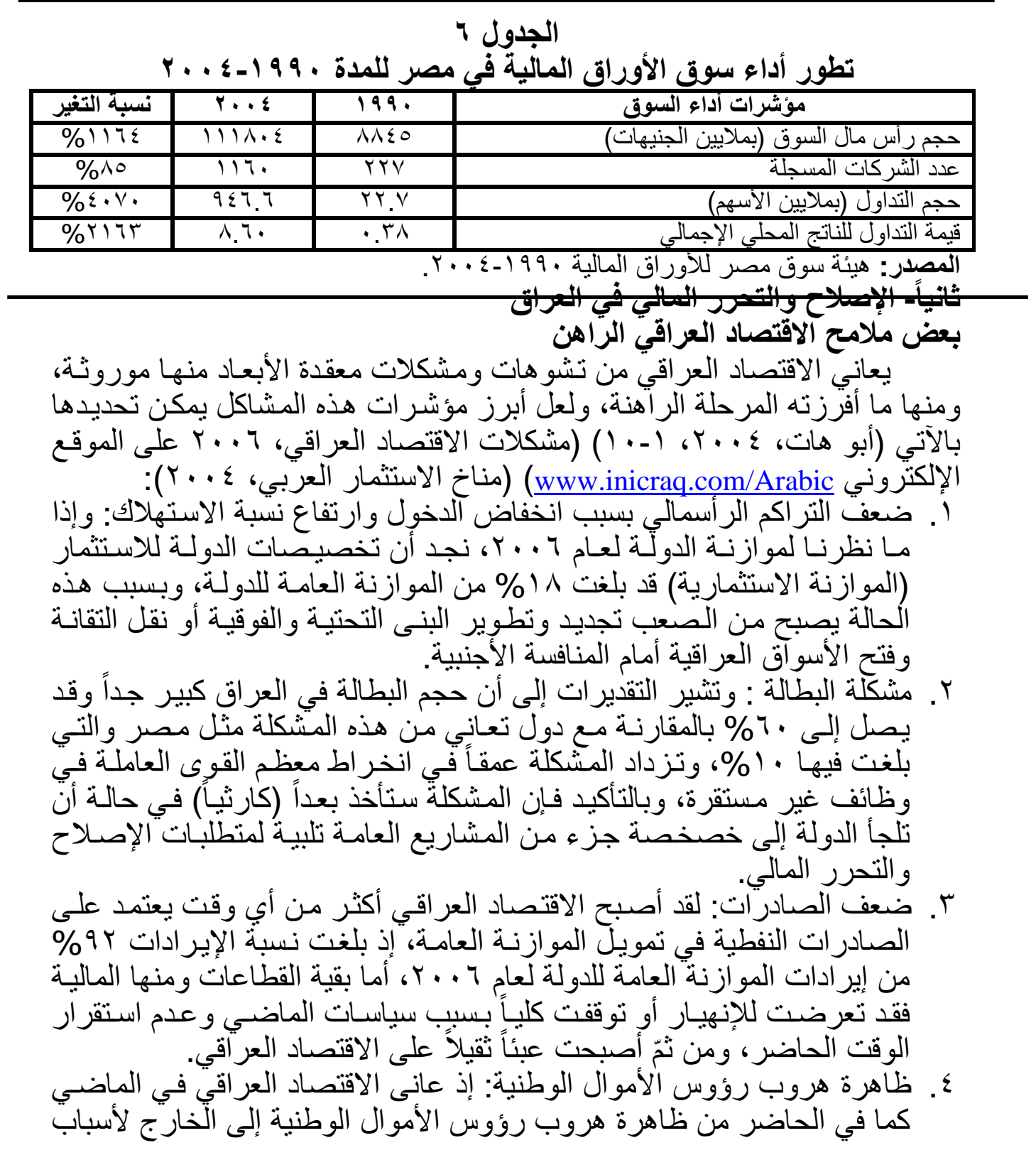




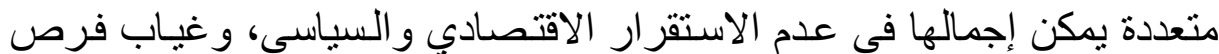

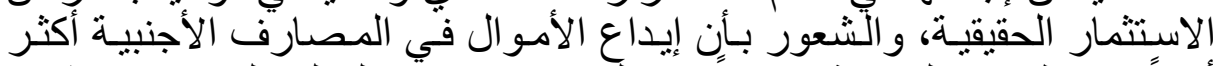

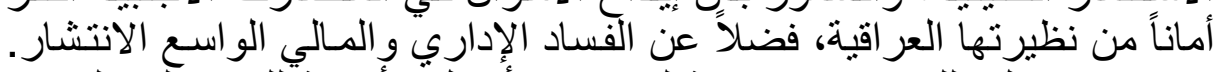

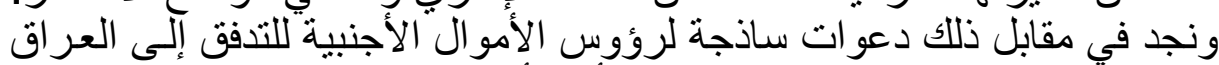

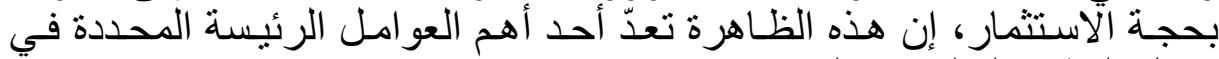

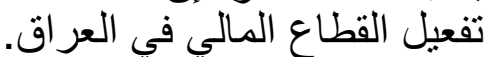

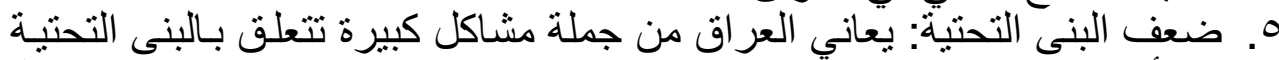

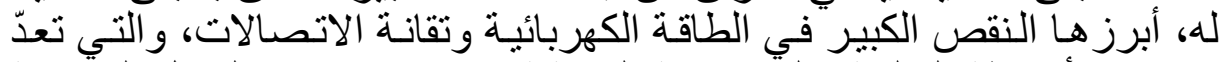

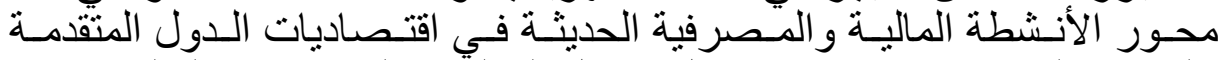

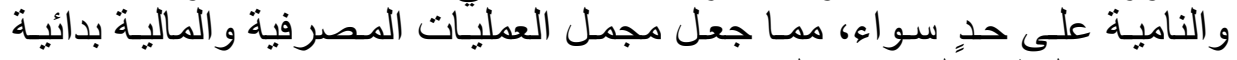
و ومدودة النطاق ألمكاني و الزماني.

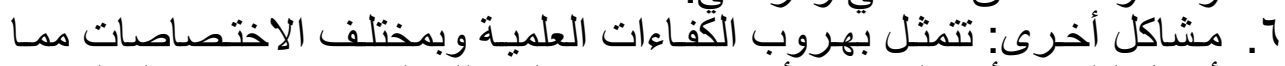

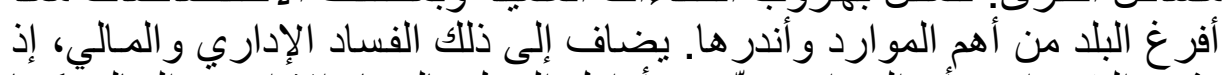

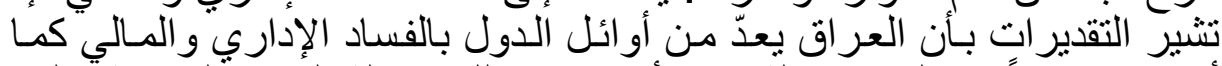

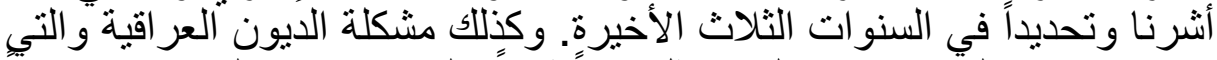

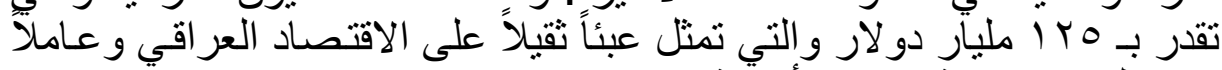
محدد لجذب الاستثمار ات الأجنبية.

إن سرد هذه المعطيات تعكس ضعف الاجنية وهشانشة الاقتصاد العر اقي، إذ لا يمكن

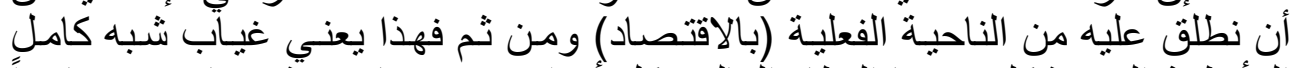

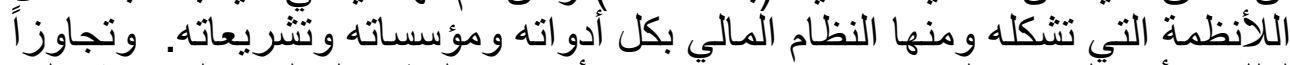

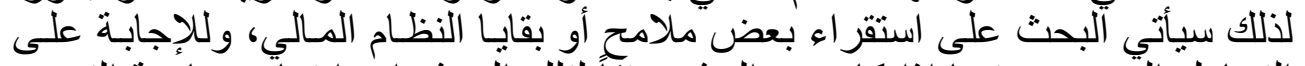

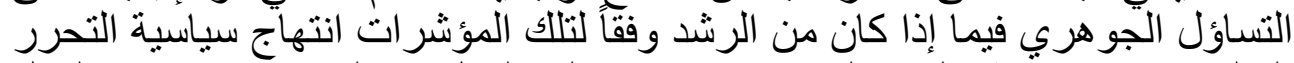

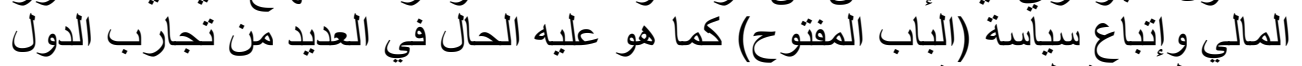
ومنهاً التجربة المصرية.

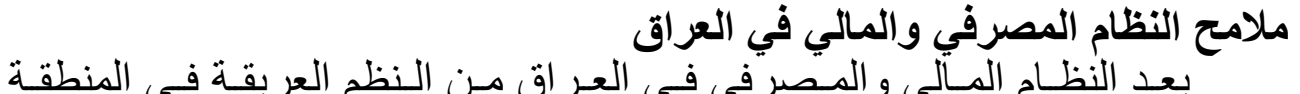

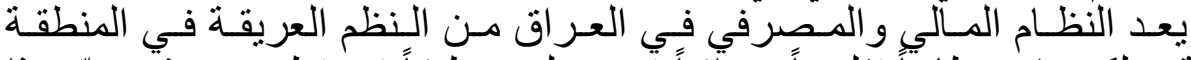

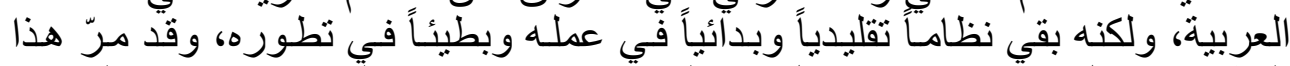

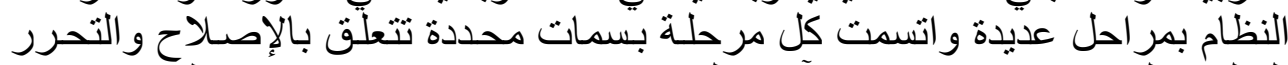

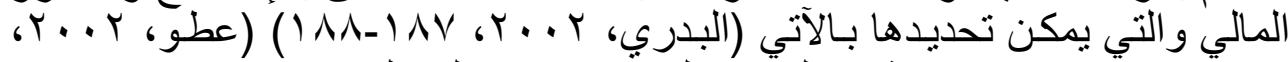

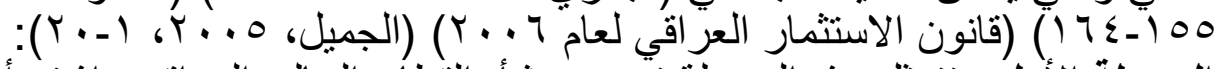

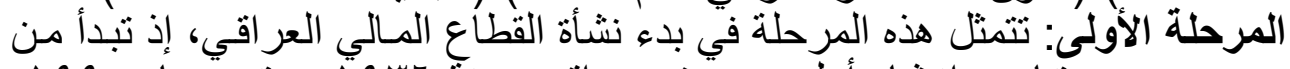

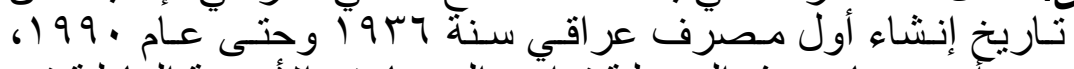

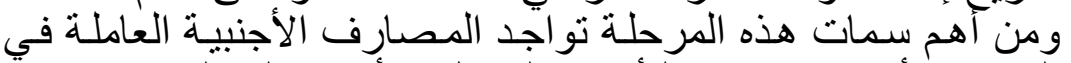

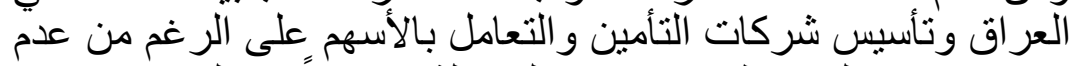

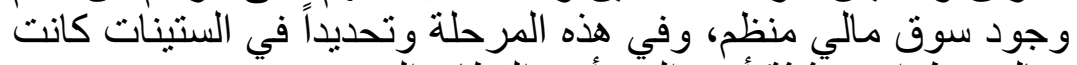

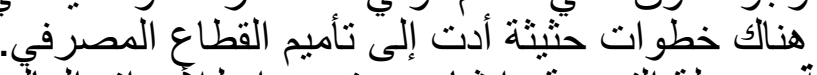

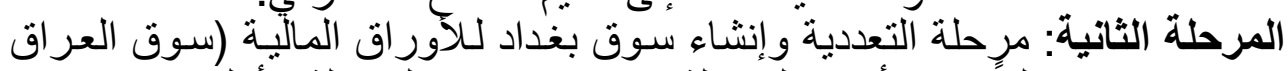

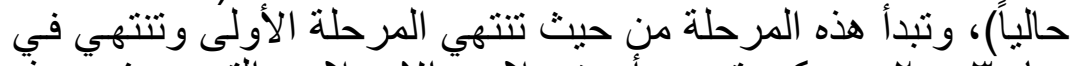

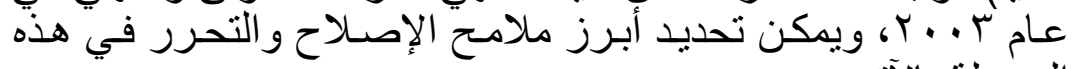

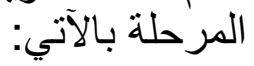


1. إنشاء سوق بغداد للأوراق المالية عام بو 99 أ.

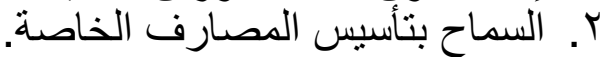

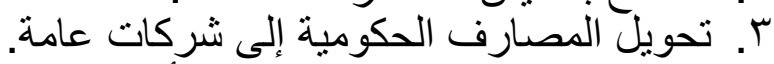

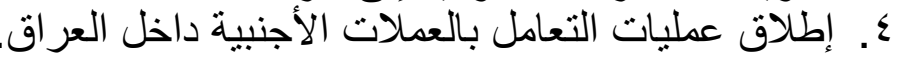

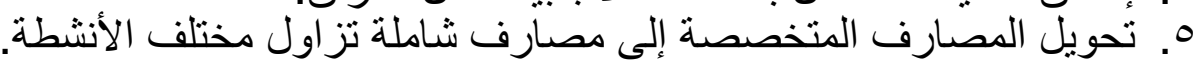

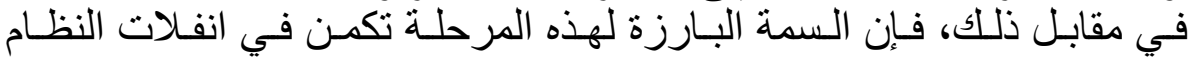

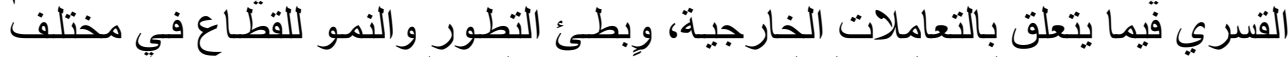

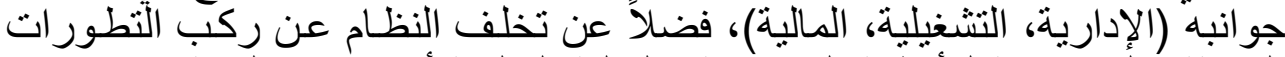
الحديثة والمتسار عة للأنظمة المصرفية المدالية والمالية العالمية أو حتى الإقليمية.

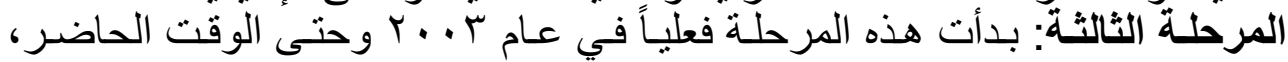

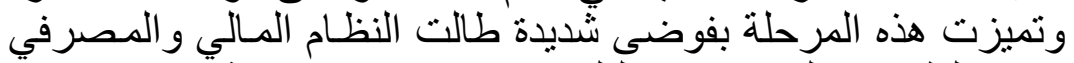

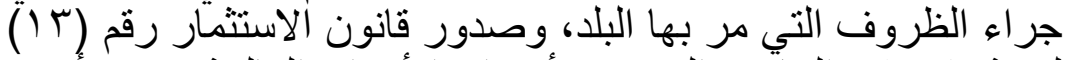

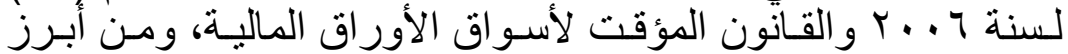
ملامح هذه المرحلة الآتي:

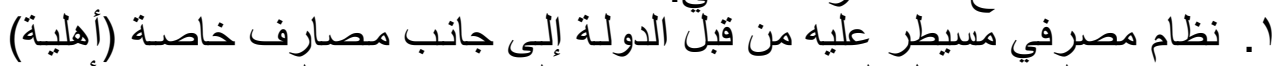

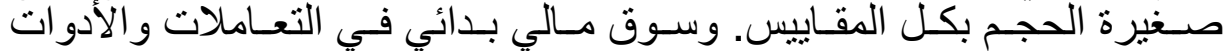

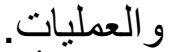
r. فقدان الأدوات المالية فاعليتها في سلم تطور النظام المالي في العر اق بسبب عدم

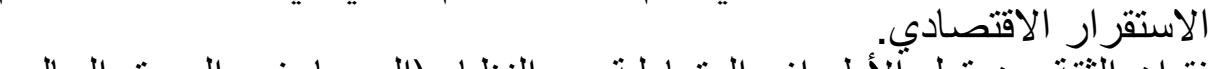
r. فقدان الثقة من قبل ألأطر اف المتعاملـة مـع النظام (المصارف، السوق المسالي،

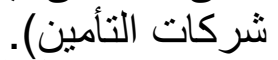
ع. غياب شبه كامل لمعلومات الإفصاح المالي وضبابية في التعاملات.

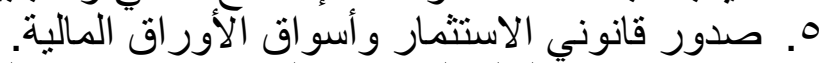

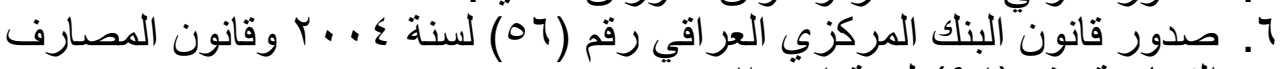

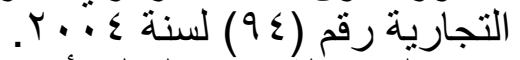

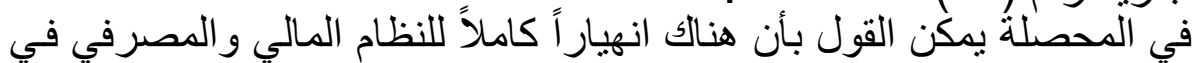

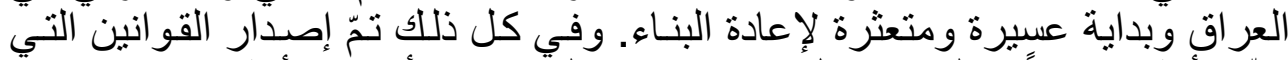

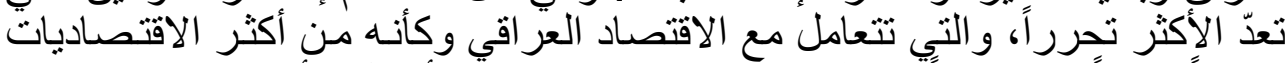

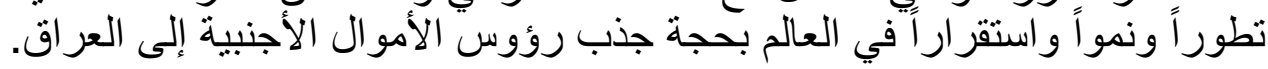

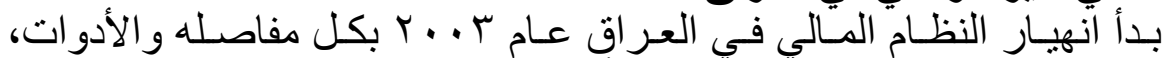

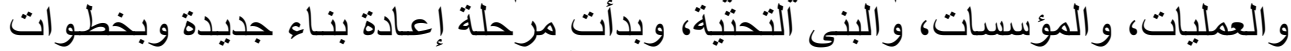

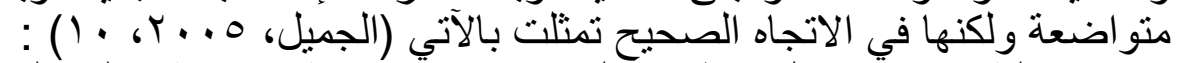

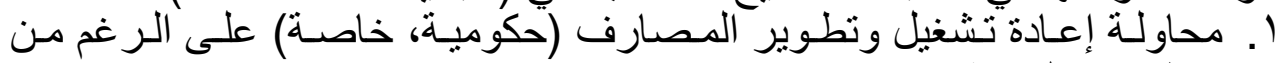
r البظومتها البدائية. r. البداء بدعم كفاية رأس المال في المصارف العالية العراقية.

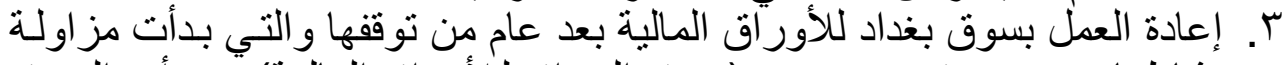

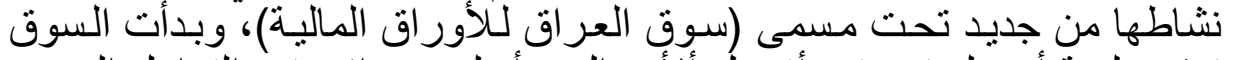
تعقد جلسة أو جلستين في أفضل ألأحو ال وبأسلوب بدائي في التداول اليوات اليوي 
دكتور الشكرجي والطائي والنعيمي [190]

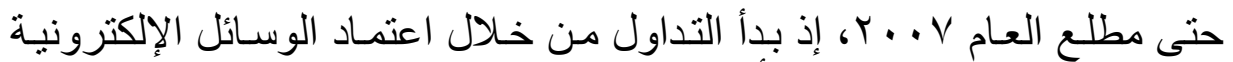

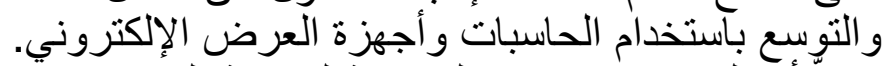

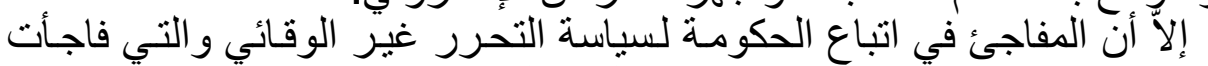

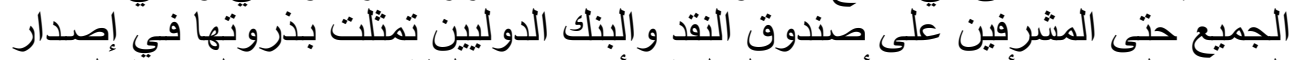

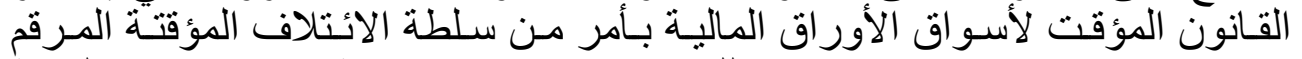

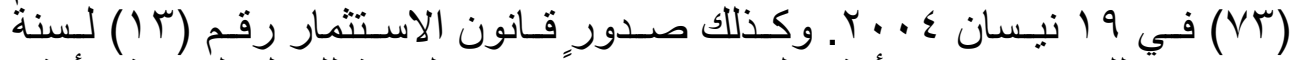

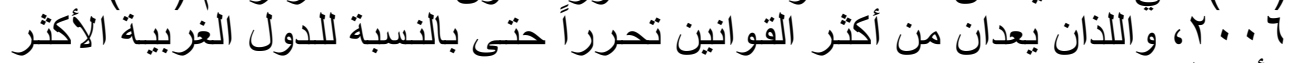

ويمكن من خلال القراءة المتأنية لفصول ومواد القانونين المذكورين آنفاً تحديد رأسمالية. أهم المحأور التي تتضندمنها بالآتي:

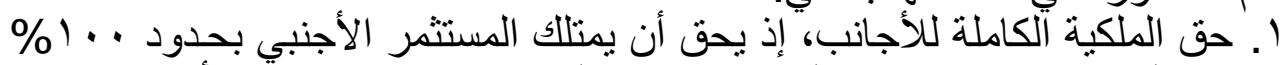

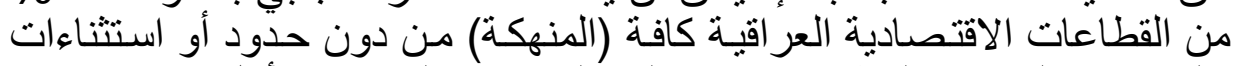

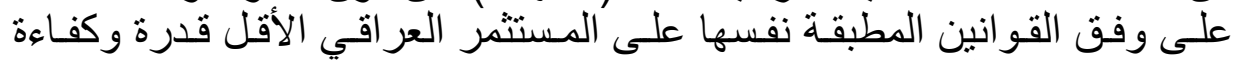
باستثناء القطاع النفطي.

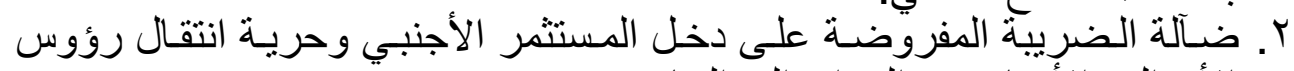

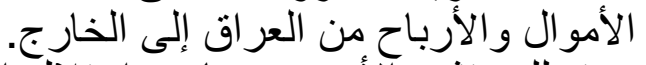

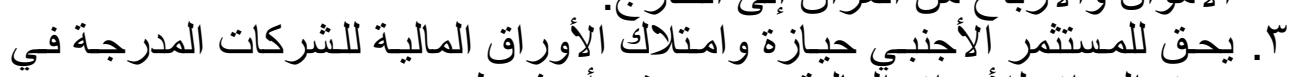

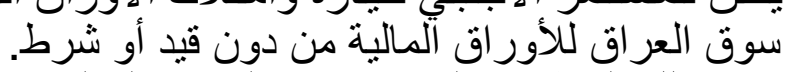

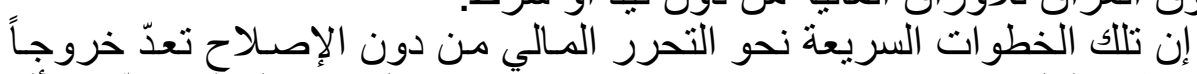

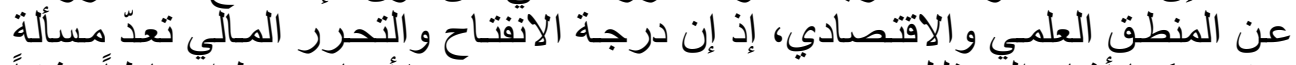

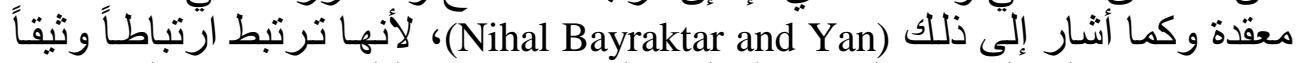

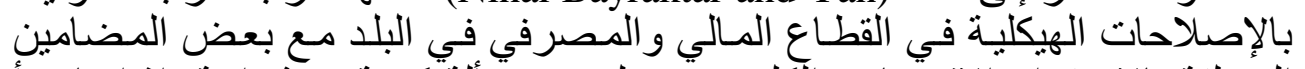

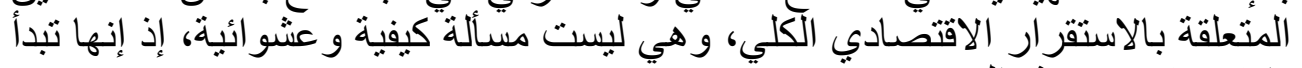
بالإصلاح ومن ثُّ التحرر (Nihal Bayraktar and Yan, 2004, 1-40)

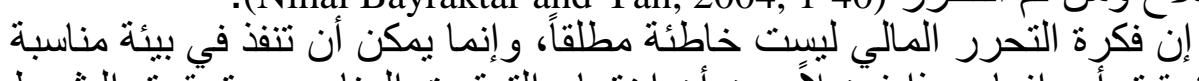

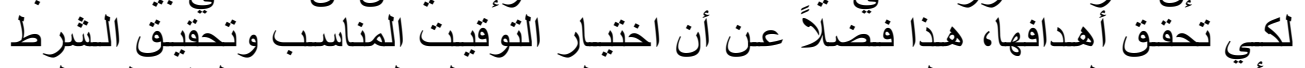

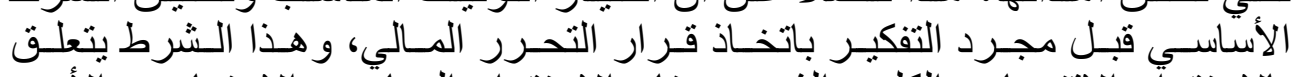

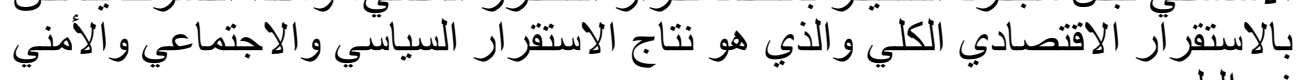

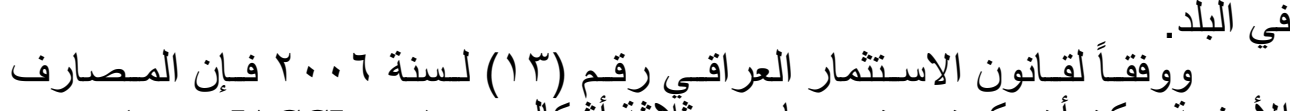

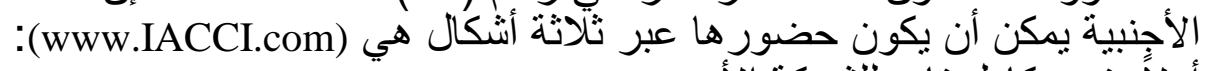

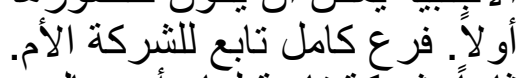

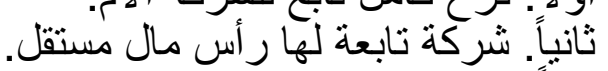

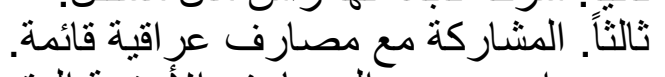

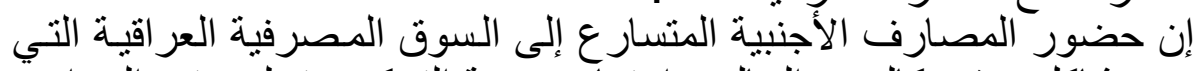

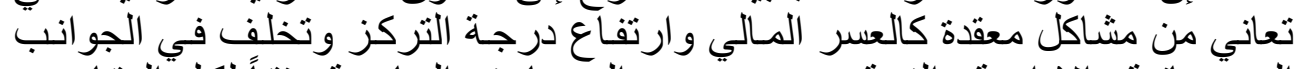

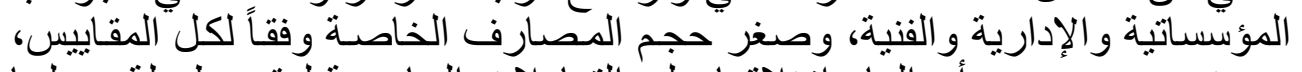

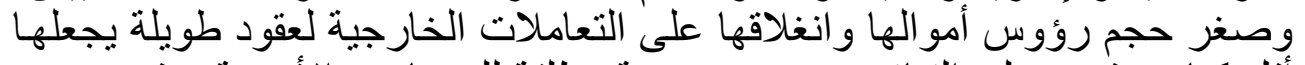

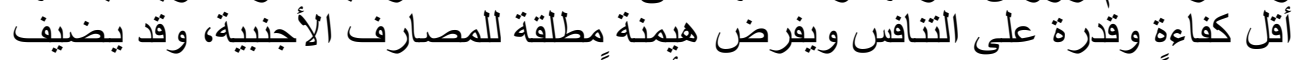

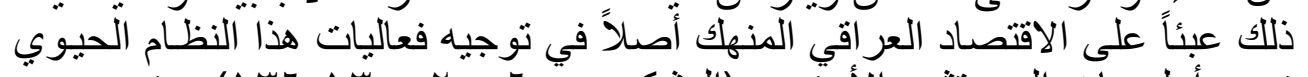

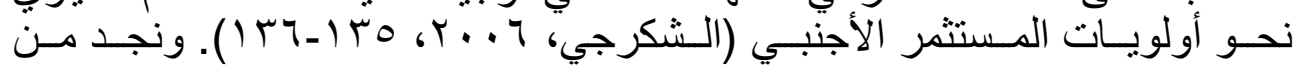


الضروري الإشارة إلى أن الثكوك وحالات التخوف من حضور المصارف التوف الأجنبية

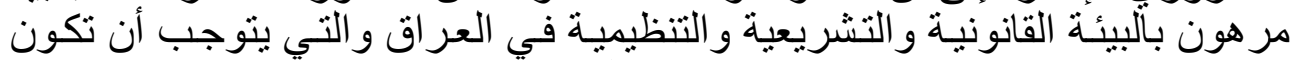

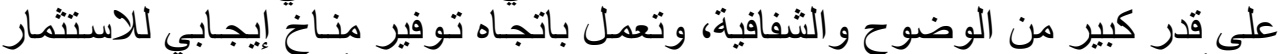

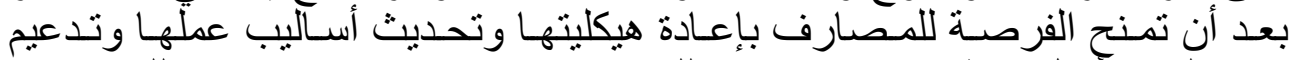

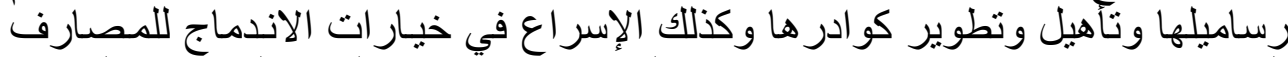

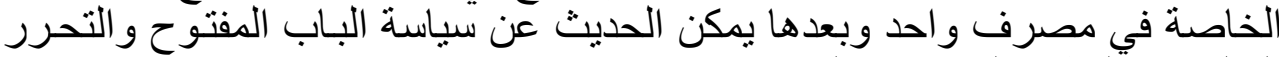

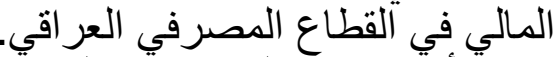

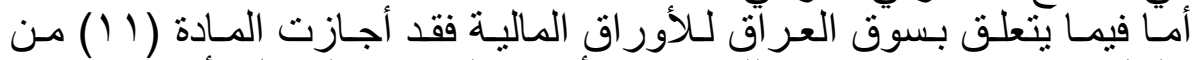

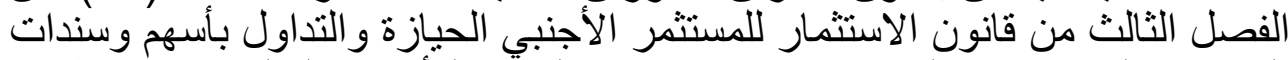

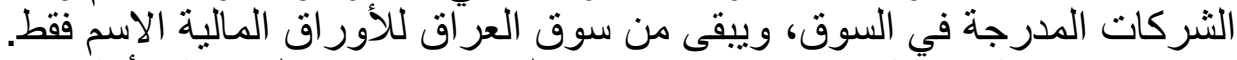

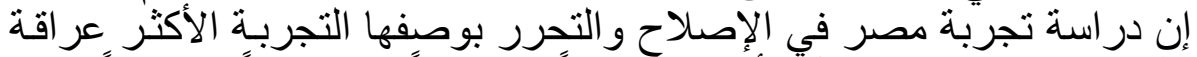

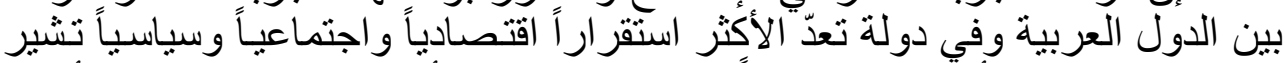

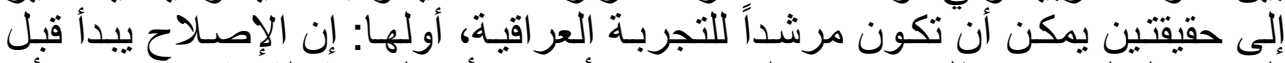

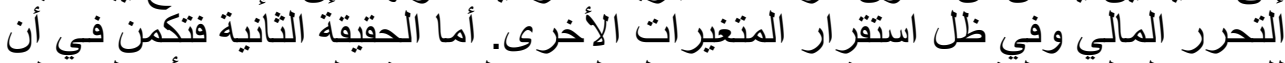

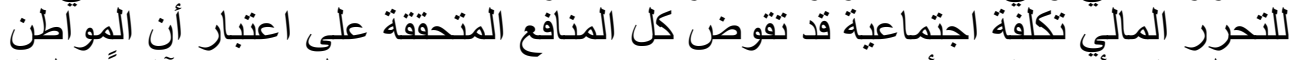

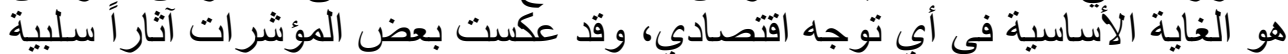

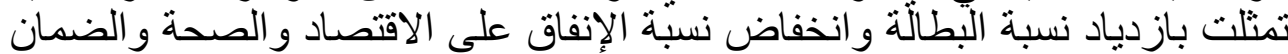

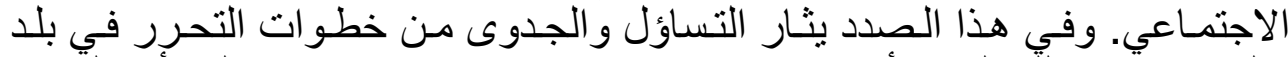

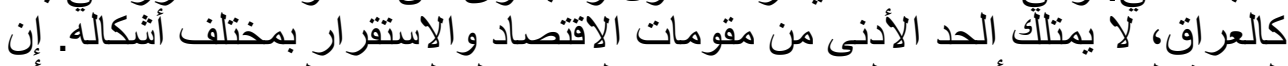

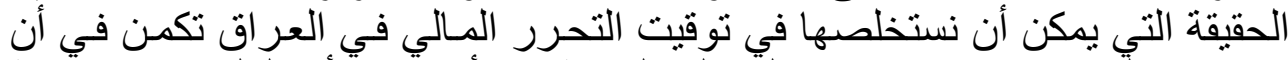

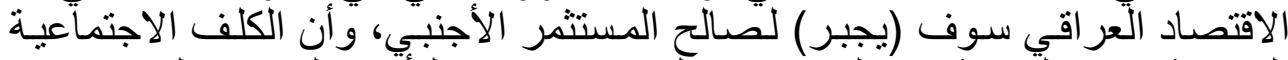

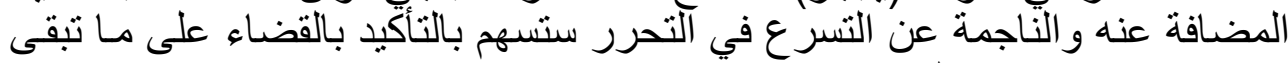
من مقومات الاقتصاد العر اقي.

الاستنتاجات

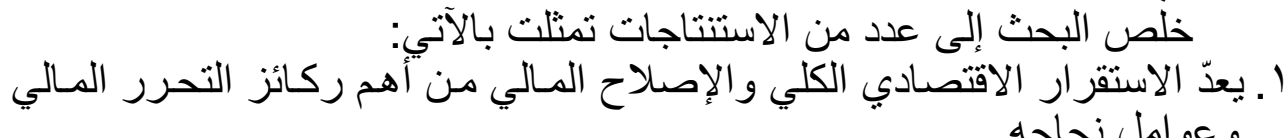

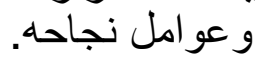

r. تتباين مناهج التحرر تبهاً للبيئة الاقتصادية التي ينطلق منها.

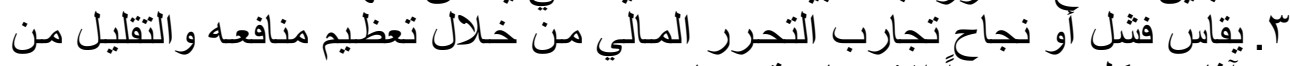

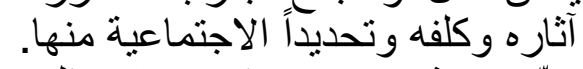

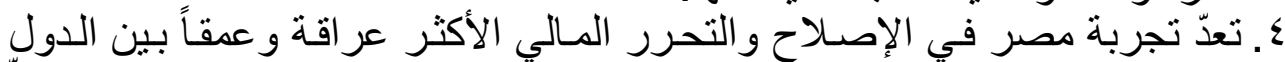

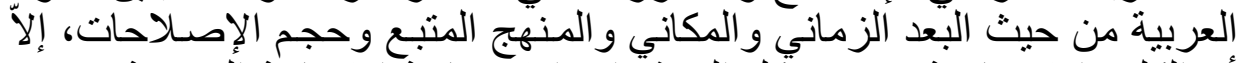
أن الكلف الاجتماعية قوضت كن كل المؤشر ات الاتي الاقتصادية الإيجابية المتحققة.

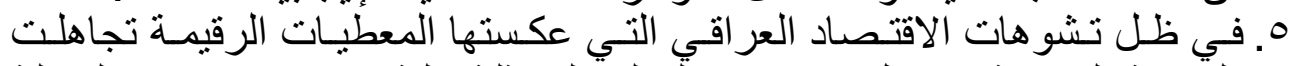

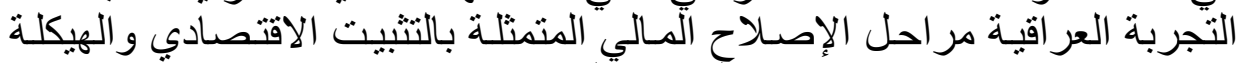

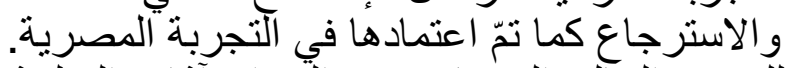

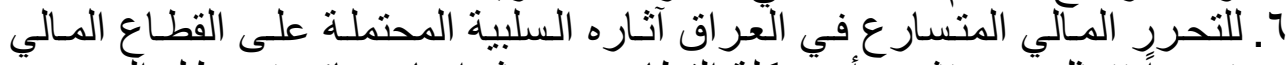

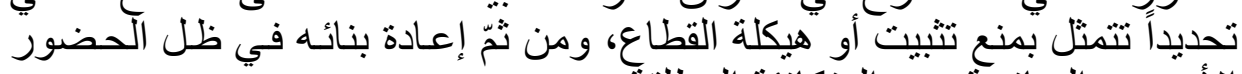

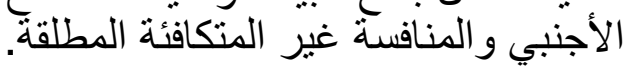


دالشتور الشكرجي والطائي والنعيمي [19V]

V. لا زال القطاع المصرفي العر اقي يمثل عصب النظام المـالي في العراق في ظل ضعف و غياب دور الأسو اق المالية.

استكمالاً لمنهجية البحث توصلنا إلى العديد من المقترحات هي:

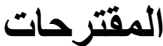

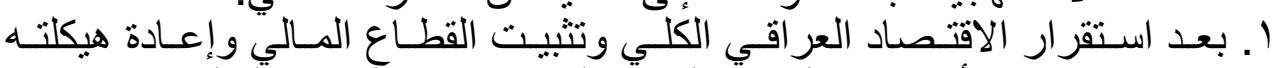

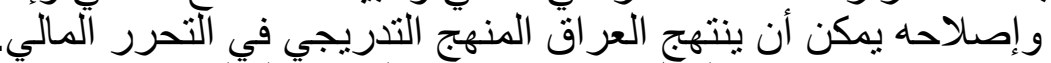

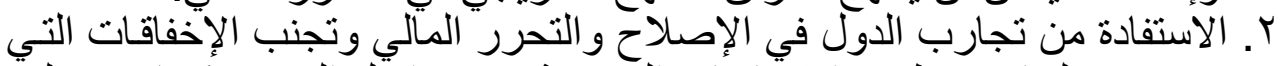

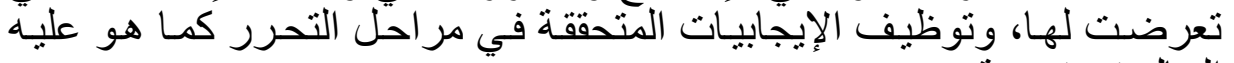

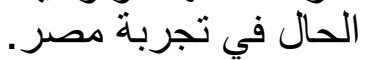

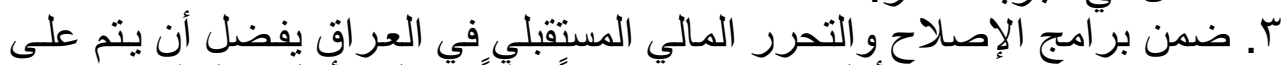

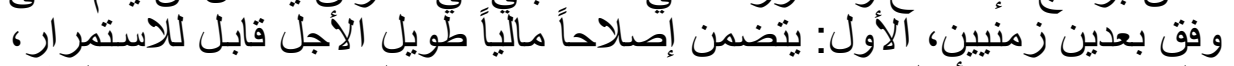

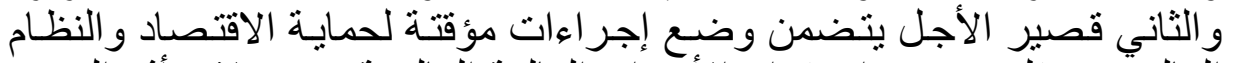

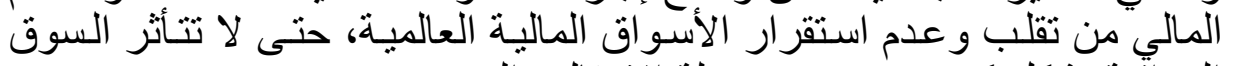

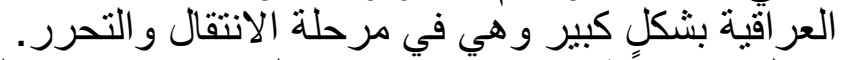

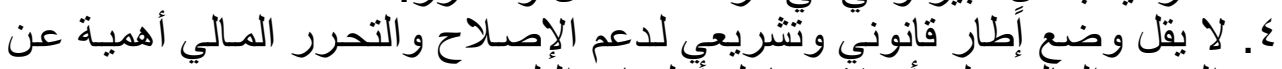

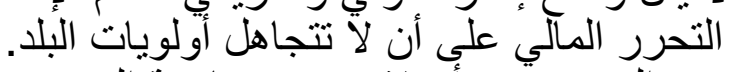

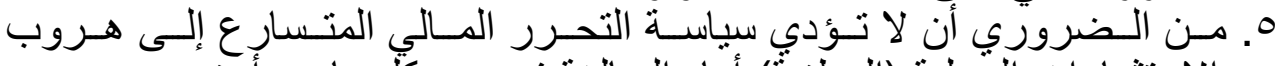

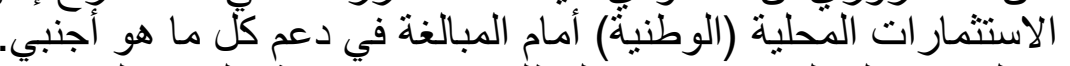

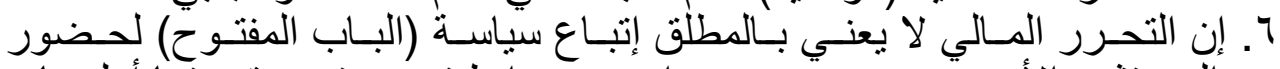

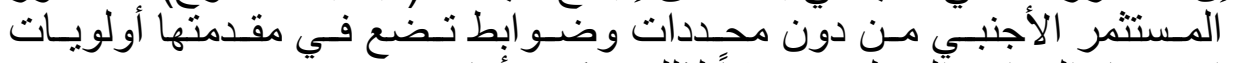

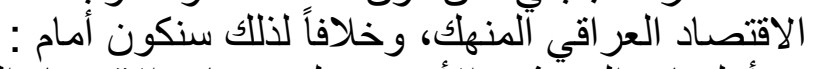

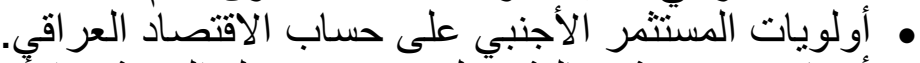

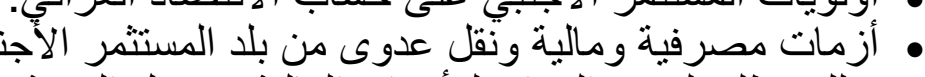

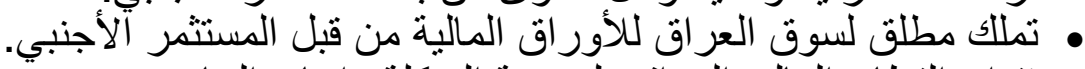

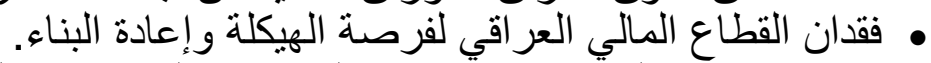

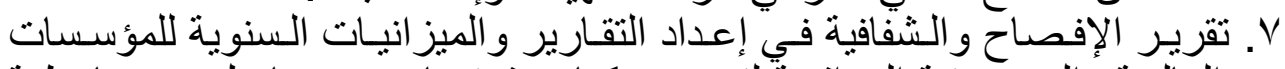

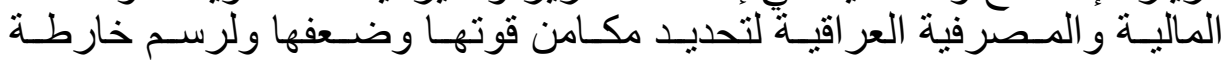

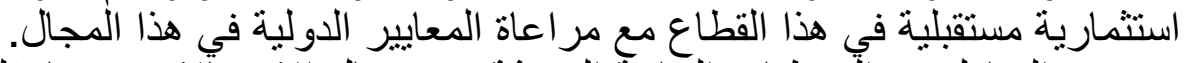

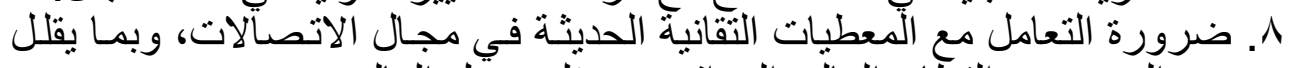

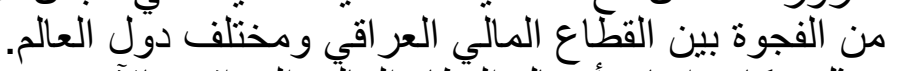
9. تتمثل ركائز إعادة أعمال النظام المالّي العر اقي بالآتي • • • • إعادة الثقة بالنظام. • • ألتشريعات والقو انين الداعمة لجها إعادة النظام المالي. • أتمتة العمليات وزيادة مهار اتلت وكفاءة الكو ادر التي تقود عملية إعادة البناء.

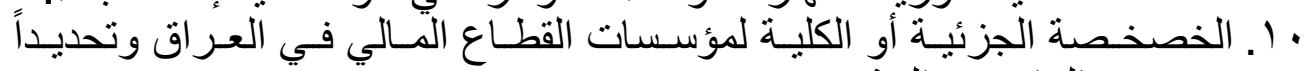
مصرفي الر افدين و الرشيد.

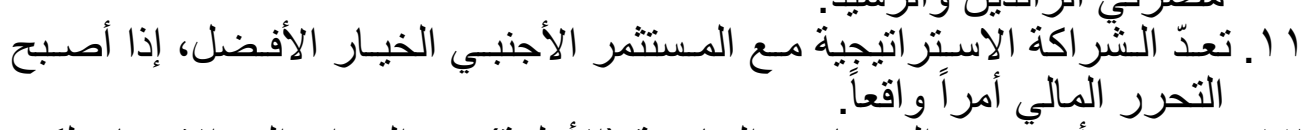

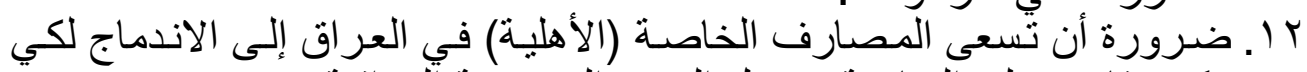
تكون قادرة على المنافسة وتفعيل السوق المصرفية الإنية آلعر اقية. 
با ـ تطوير البنية التحتية لسوق العراق للأوراق المالية الذب يعدّ من الأسواق الأكثر بدائية في المنطقة من حيث التداول. 


\begin{tabular}{|c|c|c|c|c|c|c|c|c|c|c|c|c|c|c|c|}
\hline \multirow[b]{2}{*}{ it } & \multirow[b]{2}{*}{$\Delta$} & \multicolumn{5}{|c|}{ 管 } & \multicolumn{4}{|c|}{ 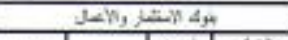 } & \multicolumn{4}{|c|}{ 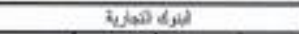 } & \multirow[b]{2}{*}{ سرت } \\
\hline & & 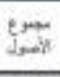 & U & (1) & Dis & سناعية & זמת & tow & $\begin{array}{l}5,3 \\
\Delta, 4 \\
4,4\end{array}$ & 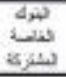 & 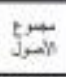 & لبسرو & شئرئ & the & \\
\hline- & 70 & 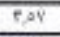 & $r+$ & 18 & $T$ & 1 & - & ? & $\div$ & 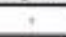 & 10,45 & a & 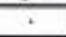 & $\circ$ & 1945 \\
\hline- & $\overline{T Y}$ & $T, 14$ & $T$. & iv & $T$ & 7 & - & $T$ & $T$ & $T$ & 4,17 & $t$ & . & $t^{t}$ & 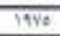 \\
\hline 40,5, & 3 & 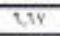 & 1 & 1 & 7 & $T$ & 14,05 & The & $\pi$ & $x$ & $v t, 11$ & 19 & 10 & T & 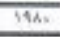 \\
\hline $190, \cdot$ & $1 i$ & 4,8 & 1 & 1 & 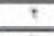 & 1 & $\mid \omega, T$ & $\pi$ & $\pi$ & 71 & $1,8,9$ & $\overline{r i}$ & $\pi$ & 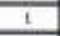 & 194 \\
\hline$(F, 5,15$ & 71 & vate & $i$ & T & $\bar{T}$ & $T$ & $1 \mathrm{LTA}$ & $\pi$ & $\pi$ & 11 & $1, n, 1$, & $\pi$ & $\pi$ & 1 & $16 \times 9$ \\
\hline $17 \times 0 \%$ & 71 & $\mathrm{NeT}$ & 1 & 1 & 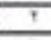 & 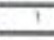 & $1,1,17$ & $\pi$ & T) & 71 & $\frac{1+1, \mathrm{kT}}{1}$ & $\overline{\nabla A}$ & $\pi$ & $t$ & कबति \\
\hline $18, \mathrm{Lik}$ & 38 & Avy & $i$ & 1 & + & 1 & $14 \cdot 4$ & $\pi$ & T. & 11 & $u, v_{2}$ & $\pi$ & $\pi$ & $i$ & 194 \\
\hline 15,14 & $\pi$ & त्ञा & $i$ & 1 & $T$ & 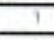 & $1 \mathrm{MN}$ & 7 & 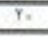 & 11 & 4,17 & तs & $\pi$ & $t$ & 5919 \\
\hline $17,2 x$ & $\pi$ & A.1. & $\mathrm{T}$ & 1 & 1 & 7 & 12,19 & $\pi$ & T. & 31 & 49,9 & $8 \mathrm{n}$ & 7 & $i$ & $5 \cdots$ \\
\hline$\frac{1 F y, \Delta r}{\mid F T}$ & $\pi$ & An. & $T$ & 1 & 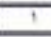 & 7 & 18,47 & 7 & $T_{+}$ & 71 & $1.6,1$. & $7 \mathrm{~s}$ & $T 1$ & $t$ & 8,1 \\
\hline- & 8 & $1+1$ & $T$ & 1 & 1 & 7 & $=$ & (1) & $\gamma_{*}$ & 31 & $11,0,4$ & $7 \mathrm{TH}$ & 74 & $\frac{1}{t}$ & $6,{ }^{\prime}$ \\
\hline
\end{tabular}

Source: Central Bank of Egypt, 2002, Annual Economic Review.

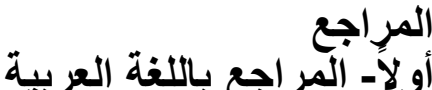

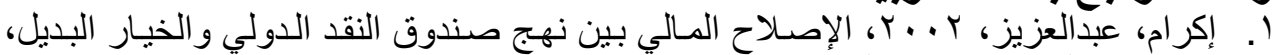

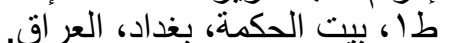

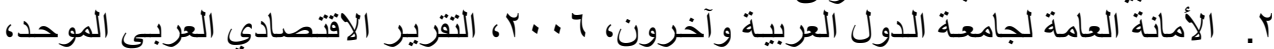

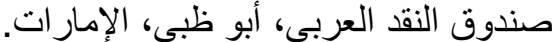

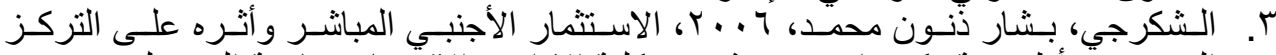

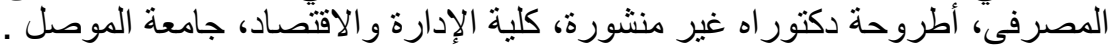

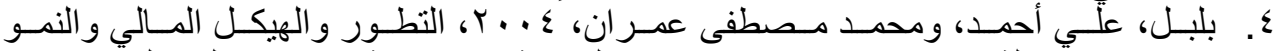

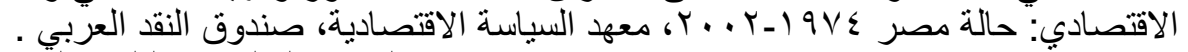

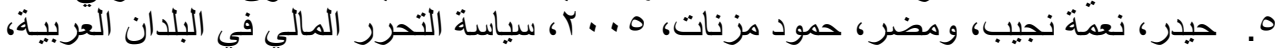

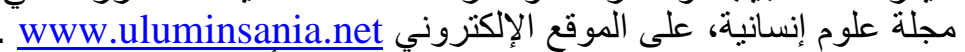

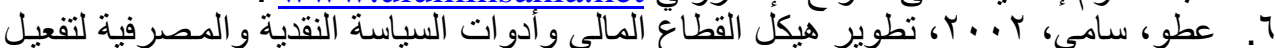

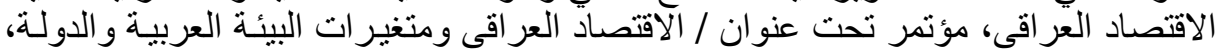

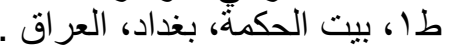

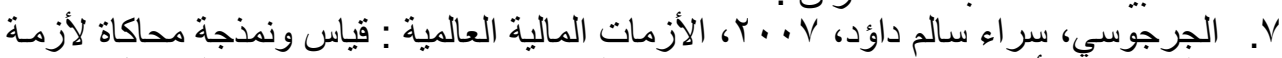

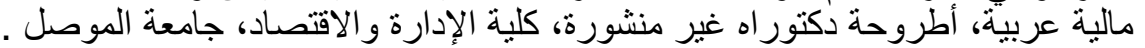

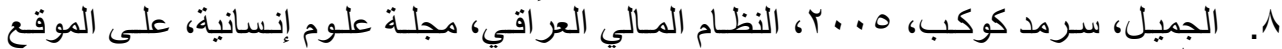

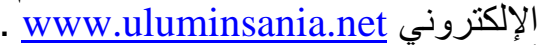

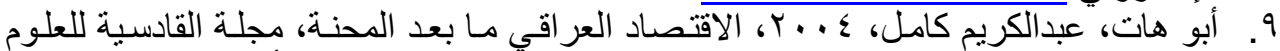

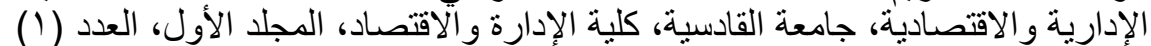

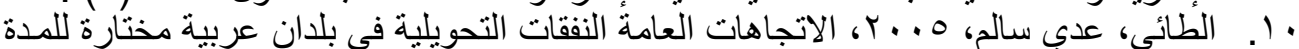

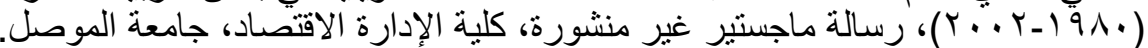

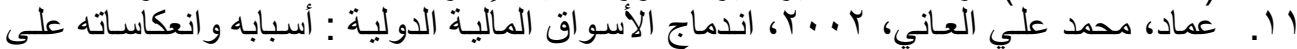

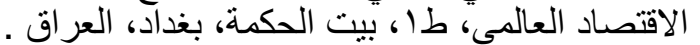

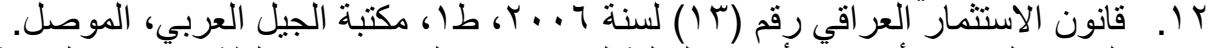

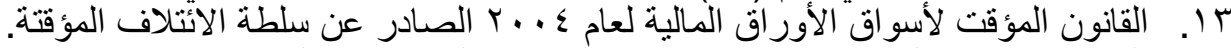

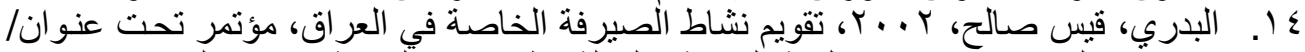

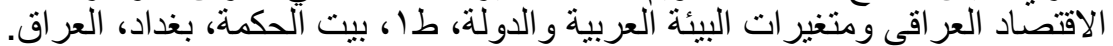

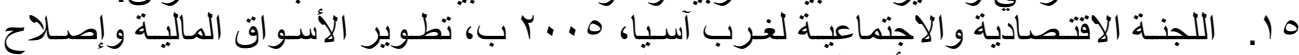
مؤسساتها، مطبو عات الأمم التنحدة، نيويورئك. 


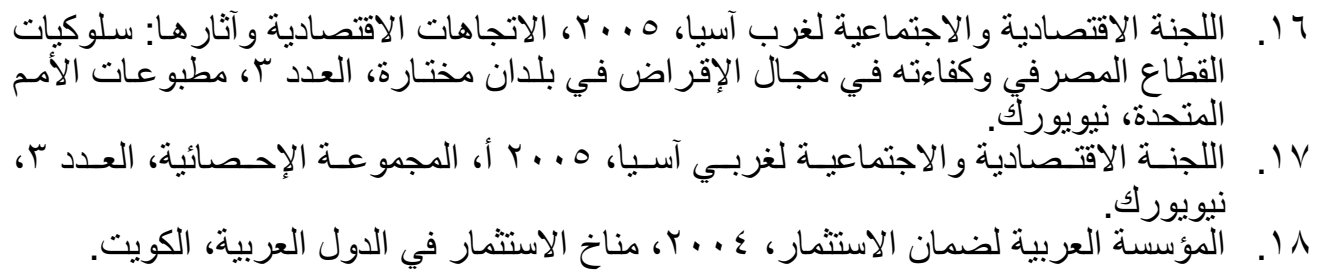

\section{ثانياً. المراجع باللغة الأجنبية}

1. Agenor, Pierre-Richatd, 2001, Benefits and Costs of International Financial, Theory and Fact, World Bank, Paper No. 19 (March).

2. Al-Mashat, R., 2001, Financial Sector Development and Economic Growth in Egypt 1960-1999, Asia and Pacific Department, International Monetary Fund.

3. Arab Stock Market Data Base, 2002, Arab Monetary Fund.

4. Berger, A. N., and T. H. Hannan, 1998, The Efficiency Cost of Market Power in the Banking Industry, Review of Economic and Statistic, Vol. 80.

5. Berthelemy, J. C. and Demurger, 2000, Foreign Direct Investment and Economic Growth, the Theory and Application to Gina, Review of Development Economic, 4 (June).

6. Central Bank of Egypt, 1994/2002, Annual Economic Review, Cairo, Egypt.

7. Central Bank of Egypt, 2002, Annual Economic Review.

8. Chang, R. and A. Velasco, 2000, Bank Debt Maturity and Financial Crises, Journal of International Economic, 51 (June).

9. Cho, Yoon, Je and Khatkate, Deena, 1989, Lessons of Financial Liberalization in Asia, World Bank Discussion Papers, World Bank, Washington.

10. Claessens, Stijn and Tom Glaessner, 1998, Internationalization of Financial Services in Asia, World Banking, Paper No. 1911 (April).

11. Demirguc-Kunt and R. Levine, 1999, Bank-Based and Market-Based Financial System, Cross Country Comparisons, Policy Research Working Paper No. 2143, Washington, D. C., World Bank.

12. Dick, K., Nanto, 1998, CRS report of Congress, the 1997-1998, Asian Financial Crisis, February.

13. Eltony, M., 2003, Quantitative Measures of Financial Sector Reform in the Arab Countries, Arab Planning Institute, Working Paper Series 0303, Kuwait.

14. Helmut Reisen and Marcelo Soto, 2001, Which Types of Capital Inflows Foster developing Country Growth? International Finance, 4 (1).

15. Isik, I., and M. K. Hassan, 2002, Cost and Profit Efficiency of the Turkish Banking Industry, The Financial Review, Vol. 37.

16. Kaminsky, Graciela L. and Sergio L. Schmuker, 2003, Short-Run, Long-Run Gain, The Effects of Financial Liberalization, NBER Working Paper No. 9787 (June).

17. Levine, R., 1996, Foreign Banking, Financial development and Economic Growth, In: C. E. Barfield (ed), International Financial Market (American Enterprise Institute Press), Washington D. C.

18. Markusen, J. R. and A. J. Venables, 1999, Foreign Direct Investment as a Catalyst for Industrial Development, European Economic Review, 43 (Feb.).

19. Micheal Gavin and Racardo Hausmannm 1999, Preventing Crisis and Contagion Fiscal and Financial Dimension, American Development Bank.

20. Nihal Bayraktor and Yan Wang, 2004, Foreign Banking Entry, Performance of Domestic Bank the Sequence of Financial Liberalization, August, World Bank.

21. Obstfield, M., 1998, The Global Capital Market, Journal of Economic Perspectives, 12 (June).

22. Omran, M., 1999, The Impact of Egypt Economic reform Programme on the Stock Market Performance, Unpublished Ph.D. Thesis, University of Plymouth.

23. Omran, M., 2003, Privatization State Ownership and the Performance of Egyptian Bank. 


\section{دكتور الشكرجي والطائي والنعيمي [ [ب]}

24. Semih H. Yildirin, 2003, Competition and Constability in Central and Eastern Markets, Thesis Presented for the Doctor of Philosophy Degree, The University of Tennessee, U.S.A.

25. The World Health Report, 2000-2006, World Health Organization, On Website: www.whoi.int. 